Florida International University FIU Digital Commons

$11-28-2000$

\title{
Exploring the role of therapy process and outcome in interventions that target adolescent identity and intimacy
}

Janene R. Bussell

Florida International University

DOI: $10.25148 /$ etd.FI14052502

Follow this and additional works at: https://digitalcommons.fiu.edu/etd

Part of the Psychology Commons

\section{Recommended Citation}

Bussell, Janene R., "Exploring the role of therapy process and outcome in interventions that target adolescent identity and intimacy" (2000). FIU Electronic Theses and Dissertations. 1996.

https://digitalcommons.fiu.edu/etd/1996 


\section{FLORIDA INTERNATIONAL UNIVERSITY}

\section{Miami, Florida}

EXPLORING THE ROLE OF THERAPY PROCESS AND OUTCOME IN INTERVENTIONS THAT TARGET ADOLESCENT IDENTITY AND INTIMACY

A dissertation submitted in partial fulfillment of the

requirements for the degree of

DOCTOR OF PHILOSOPHY

in

PSYCHOLOGY

by

Janene R. Bussell

2000 
To: Dean Arthur W. Herriott

College of Arts and Sciences

This dissertation, written by Janene R. Bussell, and entitled Exploring the Role of Therapy Process and Outcome in Interventions that Target Adolescent Identity and Intimacy, having been approved in respect to style and intellectual content, is referred to you for judgment.

We have read this dissertation and recommend that it be approved.

Wendy K. Silverman

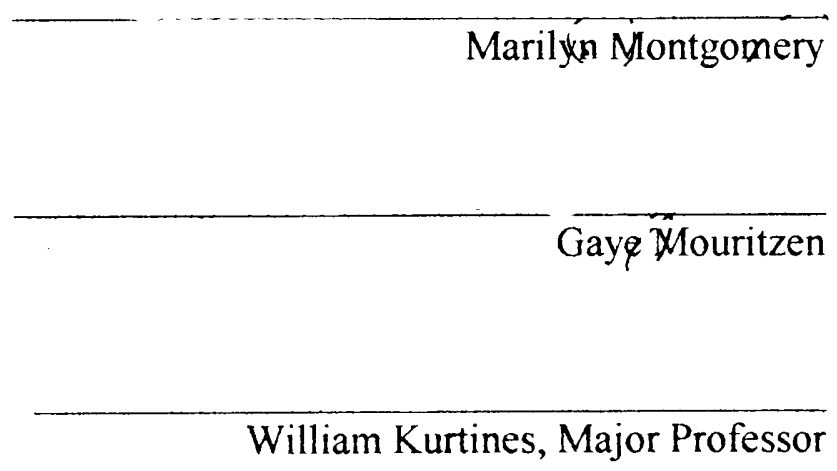

Date of Defense: November 28, 2000

The dissertation of Janene R. Bussell is approved

Dean Arthur W. Herriott
college of Arts and Sciences

Florida International University, 2000 


\section{DEDICATION}

I dedicate this dissertation to my parents. Without their guidance, understanding, support, and most of all love, the completion of this work would not have been possible. 


\section{ACKNOWLEDGMENTS}

I wish to thank the members of my committee for their support, patience, and constructive feedback throughout this process. Dr. Wendy Silverman was particularly helpful in guiding me through my literature review. The presence of Dr. Marilyn Montgomery and Dr. Gaye Mouritzen at ACE provided me with immediate support when I had questions or difficulties. I would also like to thank my major professor, Dr. William Kurtines, who had confidence in my abilities to not only complete this degree, but to complete it with excellence. Finally, I would like to thank the graduate and undergraduate students that have participated in the PYD program and who have provided me with both emotional and technical support. 


\section{EXPLORING THE ROLE OF THERAPY PROCESS AND OUTCOME IN}

\section{INTERVENTIONS THAT TARGET ADOLESCENT IDENTITY AND INTIMACY}

by

Janene R. Bussell

Florida International University, 2000

Miami, Florida

\section{Professor William Kurtines, Major Professor}

This study examined the feasibility of using a session impact measure with a sample of 24 at risk high school students participating in an intervention targeting identity and intimacy. Three therapists led 3 intervention groups with the same format. The study investigated the impact of therapy process, including Group, Facilitator, Skills, and Exploration impacts as measured by the Session Evaluation Form (SEF). The study also investigated the differential impact of session process on intervention outcome as measured by the CPSS, EPSI, RAVS, EIPQ and Youth Report Form. Analyses were conducted using descriptive statistics, frequencies, one-way analysis of variance (ANOVA), and Chi square tests. The results supported the utility of the SEF and they tentatively supported the impact of the therapist on participants' perceptions of therapeutic processes and on intervention outcome. In particular, Group 1 performed better than Group 3. This study found that the SEF is a useful session impact measure. 
I. INTRODUCTION.

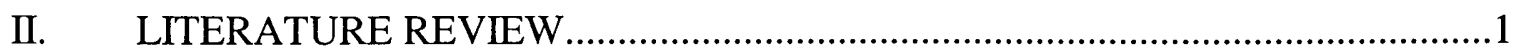

Evaluating the Impact of Therapy Process................................................................ 3

Adapting the Session Impact Scale for use in adolescent groups: The Session

Evaluation Form (SEF)....................................................................................

Evaluating Session Impact in Adolescent Group Interventions..............................8

The Population and the Problem............................................................................10

Targeting Intervention to the Developmental Moment: Identity and

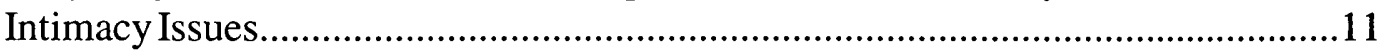

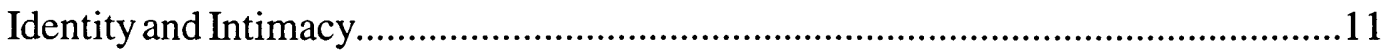

Exploration of Identity and Intimacy ..................................................................12

Individual and Group Level: Therapeutic Relationship and Group

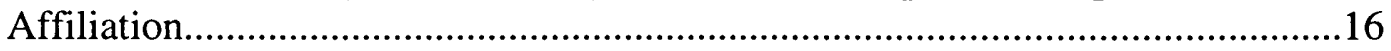

The Application of Exploration in Intervention Work.......................................17

Intervention: Promoting Youth Development Program (PYD).............................19

Toward a Solution: School-Based Group Interventions that Target

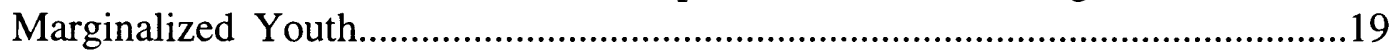

Implementing PYD in Relationship Groups...................................................21



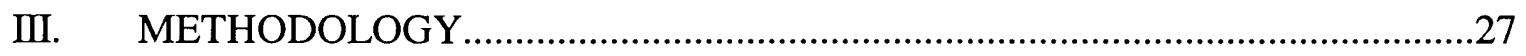

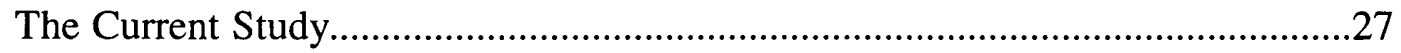

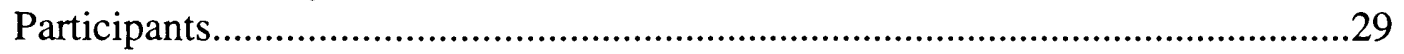

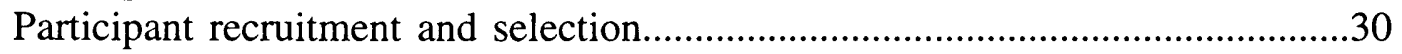

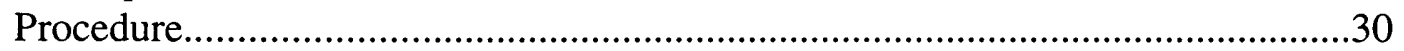

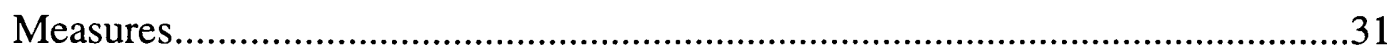

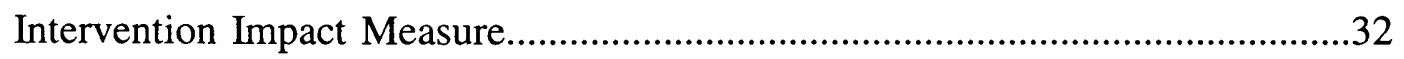

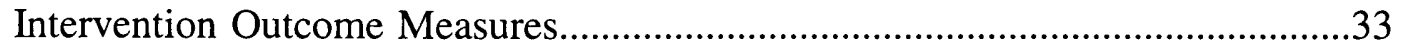

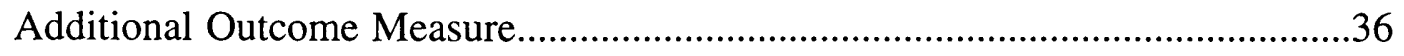

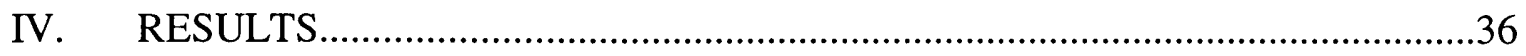

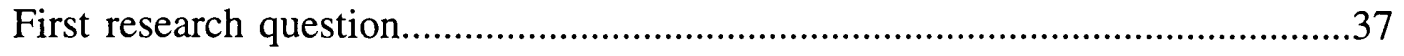

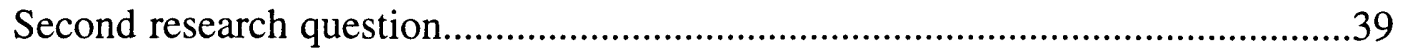

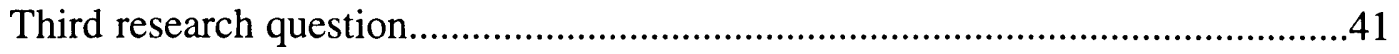

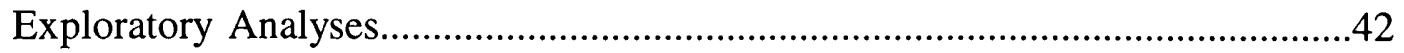




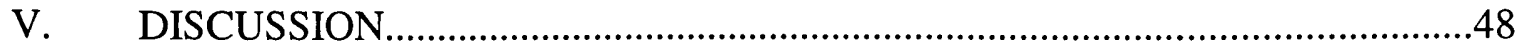

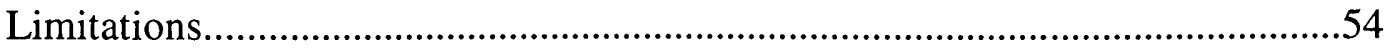

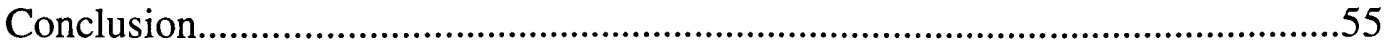

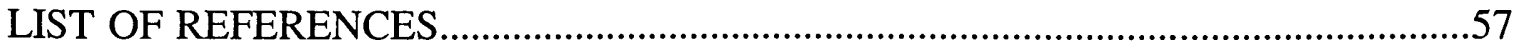

APPENDIX

VITA 
EXPLORING THE ROLE OF THERAPY PROCESS AND OUTCOME IN

\section{INTERVENTIONS THAT TARGET ADOLESCENT IDENTITY AND INTIMACY}

Historically, research on therapy processes has focused on two levels of analysis; microanalytic and macroanalytic. The microanalytic level has included moment to moment interactions between the therapist and the client and other processes that occur at the session level, while the macroanalytic level has focused on the differential impact of various modes of therapies on outcome measures (Mallinckrodt, 1994). Recently, there has been a growing interest (e.g., Elliott \& Wexler, 1994; Hill, Helms, Spiegel, \& Tichenor, 1988; Orlinsky \& Howard, 1986; Stiles \& Snow, 1984; Stiles, 1980) in developing empirical methods for assessing and evaluating the role of process variables in counseling and psychotherapy on a level that is between the microanalytic level and the macroanalytic level, i.e., on a session-by-session basis. This recent resurgence of interest in quantitatively investigating the impact of therapy process at the session level makes it possible to expand our empirically based knowledge of the relations among the therapist, therapy process, and outcome in interventions. A call has been made in the adult literature for outcome researchers to address process issues in order to obtain a more complete understanding of therapy ( Hill, Nutt, \& Jackson, 1994; Kiesler, 1986). As is the case in most areas of outcome research, the child and adolescent literature is even further behind than the adult literature. The adolescent population has been virtually ignored in terms of assessing treatment-process variables (Kaminer, 1994; Kazdin, 1995). In a review of the literature on the effectiveness of group treatment with children and adolescents, Hoag and Burlingame (1997) noted that while group therapy is an overall effective medium, research in this area lacks specific information about what makes a treatment effective. 
This is also the case for the group intervention with at risk adolescents to be implemented as part of this study. Although preliminary evidence for the efficacy of the intervention used in this study has been reported in previous studies (Ferrer-Wreder et al., 2000/in press; Lorente, 1998; 1999), no process research has been reported on the intervention. This study sought to advance the development of efficacious interventions for use with the adolescent population by helping to close the knowledge gap with respect to assessing the impact of therapy process variables in group interventions. The goal was to begin to evaluate the feasibility of assessing the impact of therapy process using a session-by-session impact measure in a difficult to work with population of adolescents in a non-clinic setting. In view of the difficulty and cost (in terms of both time and personnel resources) in collecting intervention data on at risk adolescents, the lack of previous research, and the need to establish a preliminary data base, this goal was accomplished by means of a preliminary feasibility process study conducted in a field setting with the target population. The aim was to evaluate the appropriateness of the measure as well as to pilot-test and refine procedures for administering the measure in the group interventions on a session-by-session basis and for scoring the evaluations across sessions. A further goal for this preliminary feasibility study was to develop ways for keeping the difficult to work with adolescent participants engaged in the evaluations, and to collect some initial baseline data with respect to the measure's capacity to differentially assess the impact of process across intervention groups within the sample. A final goal was to begin to explore the impact of therapy process in the groups (as assessed session by session) on intervention outcome. 
In this context, the results of this study have the potential to contribute to our knowledge of methods for designing more effective interventions for this population. The focus of this study was on investigating the feasibility of using a session impact measure with a sample of adolescents in a school-based setting and on the utility of the measure in terms of its capacity to assess the differential impact of therapy process and of the differential impact of process on intervention outcome. A further aim of this study was to begin to investigate the impact of therapy process and its relationship to intervention outcome in a sample of middle adolescent at risk high school students, a population that has increasingly become the target of psychosocial intervention.

The first part of this paper describes a growing interest in developing empirical methods for assessing and evaluating processes in counseling and psychotherapy that make it possible to empirically evaluate the impact of process variables on a session-bysession basis. This literature provided the basis for the measure evaluated in this study. The second section describes the theoretical approach behind this intervention and then it describes the intervention itself. The third section outlines the methods and procedures that were used with this population. The final sections describe and then discuss the results of this study.

Evaluating the Impact of Therapy Process

In the literature, process refers to the events that take place during a group session while outcome refers to changes that occur as a result of the intervention (Hill \& Corbett, 1993). The majority of process research to date has focused on the moment-to moment interactions between the therapist and the client(s) or on significant events that occur during individual therapy sessions (Hill, Nutt, \& Jackson, 1994). There has, however, 
been an increasing interest (e.g., Elliott \& Wexler, 1994; Hill, Helms, Spiegel, \&

Tichenor, 1988; Orlinsky \& Howard, 1986; Stiles \& Snow, 1984; Stiles, 1980) in developing methods for assessing and evaluating the impact of process variables in therapy on a session-by-session basis. These measurements taken on a session-by-session basis are referred to as measures of impact.

"Measures of impact are concerned with clients' internal reactions to sessions, which, logically, must intervene between in-session events and the long-term effects of treatment" (Stiles et al., 1994) p. 175.

This shift in focus from a moment-to-moment level to a session-by-session level of analysis occurred in an effort to obtain useful information at a more microanalytic level while avoiding the difficulty and complexity that goes along with analyzing a session on a moment-to-moment basis (Mallinckrodt, 1994; Stiles, 1980). The session-level is also useful because it allows researchers to examine therapeutic impact from a middle-level of analysis that is not as cumbersome as moment-to-moment interactions and is more detailed than a client satisfaction questionnaire (Elliot \& Wexler, 1994).

Over the past twenty years, there have been a number of measures developed that have focused on the therapy process on a session-by-session basis, with most designed for use with adults in individual therapy. A search of the literature revealed only one session impact measure used in individual therapy with adolescent males (Dunne, Thompson, \& Leitch, 2000) and only one session impact measure being used in adolescent groups (Kaminer et al, 1998). Kaminer et al. (1998) c ' amined the Group Sessions Rating Scale with adolescent substance abusers. It was suggested that it could be used as a model for other populations; however, it was used with a clinical population and designed 
specifically for assessing substance abuse groups and distinguishing interpersonal therapy from cognitive behavioral therapy. In the adult literature, a number of researchers have responded to the call for more information (Hill \& Corbett, 1993) about the impact of therapy process on different types of clients, using different interventions, and in different therapeutic circumstances. The result has been the development of a number of measures for assessing treatment impact on a session by session basis. The adult literature thus provided a more diverse array of potential measures of session impact to draw on in developing a measure for use with group interventions with at-risk adolescents.

One of the earliest and most often cited measures in the adult literature (Hill, Nutt, \& Jackson, 1994) was Stiles' (1980) Session Evaluation Questionnaire. The Session Evaluation Questionnaire was briefly used to examine the affective impact of group sessions, but then became more popular as a measure of session impact during individual therapy sessions (Stiles, 1980; Stiles, Tupler \& Carpenter, 1982; Stiles et al., 1994). The Session Evaluation Questionnaire was designed to measure the client's emotional reaction to the session impact by using sets of bipolar adjectives. The Session Evaluation Questionnaire's focus on the mood of the client does not allow it to address any of the content of the session (Elliot \& Wexler, 1994; Mallinckrodt, 1994), which is one of the primary goals of the school-based intervention used in this study.

Orlinsky and Howard's $(1975,1977,1986)$ measure, the Therapy Session Reports, was developed to examine session impact more comprehensively than the Session Evaluation Questionnaire. The Therapy Session Reports is more comprehensive because it is more content-oriented, it provides a scale for rating the session effectiveness, and a scale to measure client satisfaction. The Therapy Session Reports, however, is time 
consuming to administer and therefore involves considerable subject burden, with most versions containing anywhere from 147-168 items.

Phillips (1986) developed the Shapiro Personal Questionnaire that used a different approach to measuring session impact by examining symptom or problem change on a session-by-session basis. The Shapiro Personal Questionnaire consists of a list of problems compiled by the patient and a weekly rating indicating how much each problem has bothered the client since the last session (Phillips, 1986). This approach is useful with clinical populations, but may not be as useful in an intervention setting where there are not always clearly diagnosable presenting problems or symptoms.

Elliott and Wexler (1994) reported psychometric data on a 16-item measure of the impact of individual psychotherapy sessions. This measure was derived from earlier cluster and content-analytic studies (Elliott, 1985; Elliott, James, Reimschuessel, Cislo, \& Sack, 1985) of clients' open-ended descriptions of significant therapy events. The measure, the Session Impact Scale, is a session-level rating scale that provides a quantitative measure of the impact of therapy process. This impact measure made it possible to empirically evaluate both task and relationship process on a session-bysession basis.

The Session Impact Scale consists of three main subscales. The first two scales, Task Impacts and Relationship Impacts consist of 5 items each and can be combined into a larger scale called Helpful Impacts. The third scale, Hindering Impacts, consists of 6 items. All items are rated on a 5-point Likert scale $(1=$ not at all, $2=$ slightly, $3=$ somewhat, $4=$ pretty much, and $5=$ very much). Elliot and Wexler (1994) provided support for the psychometric status of the Session Impact Scale. The internal reliabilities 
for the scales were good (alphas= Task Impacts, .84; Relationship Impacts, .91; and

Hindering Impacts, .67). Convergent validity data were good as indicated by conceptually meaningful correlations with other measures of session impact. Construct validity was also supported by several lines of evidence including factor analysis results consistent with the hypothesized factor structure of the measure and evidence for discriminant validity as indicated by a lack of correlation with unrelated measures of session process variables. Research demonstrates that the Hindering Impacts scale is not as reliable as Helpful Impacts scale and items in this scale are not endorsed as often, which can lead to a difficulty with analysis (Elliot \& Wexler, 1994; Stiles et al., 1994).

Adapting the Session Impact Scale for use in adolescent groups: The Session Evaluation Form (SEF)

From the review of the literature, the Session Impact Scale emerged as the measure most appropriate for the research goals of this study. The Session Impact Scale is relatively short and easy to administer and many of the Task Impact and Relationship Impact items on the Session Impact Scale appeared readily adaptable for use in assessing session impact in school-based adolescent group interventions. The Session Impact Scale, however, was designed for individual therapy sessions with an adult population.

The Session Evaluation Form (SEF; Bussell \& Kurtines, 1999) that was used in this study, consequently, is an adaptation of the Session Impact Scale, refined and extended for use in adolescent groups in non-clinic settings. The SEF was developed for use in group work with adolescents by adapting a number of items from the Session Impact Scale and constructing a number of content specific task impact items to tap specific domains targeted by the intervention used in this study. The SEF is thus a session 
impact measure for use in intervention groups with adolescents. It was designed to be administered at the end of each group session and consists of two subscales measuring relationship impacts and two subscales measuring task impacts that are used as markers of therapy process. More specifically, two of the subscales (Group Impact and Facilitator Impact) assess the group participant's perception of the impact of group cohesion, group support and therapist support during that session. The other two subscales (Skills Impact and Exploration Impact) assess the group participant's perception of the impact of the skills and knowledge development training and the impact of exploration enhancement (these strategies are described in more detail in the intervention section) on their selfdevelopment during that session.

It should be noted that the SEF does not assess the impact of all possible therapeutic processes in group interventions. In their review of the literature, for example, Beck and Lewis (2000) pointed out that group process research focuses on four components of group therapy -- how the group develops as a whole, client-therapist relationships, client-client relationships (e.g., dyadic peer relations) and therapisttherapist relationships (e.g., relations between co-leaders). Rather than target all four components, the SEF instead focuses on two the types of relationship impacts (group and facilitator) and on the two types of task impacts (skills acquisition and personal exploration) of therapy process that are most salient in our work, thereby minimizing participant burden created in administering the measures.

\section{Evaluating Session Impact in Adolescent Group Interventions}

As contemporary youth have become increasingly vulnerable to negative developmental outcomes, the recognition of the need to develop interventions to address 
this population has grown (Dahlberg, 1998; Rutter, 1990; Rutter, Giller, \& Hagell, 1998). One important consequence of this recognition has been more extensive effort directed toward developing and evaluating school-based interventions designed to reduce youth risk for problem behavior (e.g., Botvin \& Dusenbury, 1987; Durlak, 1998; Gesten, Weissberg, Amish, \& Smith, 1987; Kirby, 1997; Webster-Stratton \& Taylor, 1998; West, 1991). In addition to the recognition of the need for more intervention research, a call has been made to address treatment-process issues in the adolescent literature (Hoag \& Burlingame, 1997; Kaminer, 1994; Kazdin, 1995). As mentioned above, this study addresses these challenges by using a session impact measure to evaluate an adolescent intervention and to begin to examine treatment-process issues. More specifically, it was expected that the SEF would have the ability to measure different levels of the impact of the processes outlined above as perceived by the participants. Furthermore, it was expected that positive session impact evaluations as measured by the SEF would be related to improvement on the outcome measures. Thus, the resurgence of interest in developing measures of the therapeutic process makes it possible to expand our knowledge of the impact of process variables in general and the resurgence of interest in developing interventions to address the needs of at risk youth makes it possible to expand our knowledge of what is needed in order to develop effective interventions with this population. Furthermore, as discussed below, this study was conducted as part of an ongoing program of theoretical and applied research aimed at promoting positive development in disadvantaged urban high school youth. 


\section{The Population and the Problem}

Contemporary youth have become increasingly alienated from the mainstream social institutions (economic, political, familial, educational, etc.) that have traditionally provided young people value references and normative support. The costs to society have been high (Côté, 1994; Tait, 1993). As a consequence of the experience of growing marginalization, young people have invested less and less in normative social institutions. These youth have withdrawn from proactive participation in their personal lives, tending not to take control and responsibility for the direction of their lives, instead searching for daily adventure that too frequently includes the type of antisocial activities and problem behaviors that give rise to the growing concern over the future of these young people (Gardner, Green, \& Marcus, 1994). This disengagement of youth has also had psychological costs. It has, for example, had a negative impact on developmental outcomes for many young people (Côté \& Allahar, 1994).

In the United States, a large proportion of marginalized young people come from inner-city, low-income minority families that exist within a community context of disempowerment, limited access to resources, and pervasive violence, crime, and substance abuse (Berman, Kurtines, Silverman, \& Serafini, 1996; Gardner, Green, \& Marcus, 1994; Wilson, Rodriguez, \& Taylor, 1997). Daily they face the challenges of growing up in a context that confronts them with many difficult life choices: pressures to use drugs, get involved in gangs, and engage in sexual activities; issues of making friends and resisting peer pressure; problems with trust and anger management; parental conflicts and family dysfunction; issues about intimacy, teenage parenting and gender identity; exposure to crime, violence, and abuse; and general concerns about their own futures. 
Targeting Intervention to the Developmental Moment: Identity and Intimacy Issues

This study was conducted as part of an ongoing program of co-constructivist theory and research (Berman, Schwartz, Berman, \& Kurtines, 2000/in press; Ferrer, et al., 2000/in press; Kurtines, 1999). This co-constructivist approach extends earlier work on identity development by providing a framework for developing interpersonal intervention strategies for promoting positive development in terms of both identity and intimacy issues in youth.

Identity and Intimacy. In targeting the developmental moment, this work draws its developmental framework from an Eriksonian (1968) approach, which is both life span and psychosocial in orientation. Erikson (1968) recognized that the identity achieved during adolescence would continue to develop and evolve throughout the remainder of an individual's life. The approach used in this study, consequently, not only targets the type of identity issues that define the developmental moment for these young people, it draws on the Eriksonian view that the successful resolution of earlier life tasks is foundational for successfully meeting subsequent life challenges. In the context of this dynamic process, the program that we have been developing, the Promoting Youth Development (PYD), not only targets (and seeks to resolve) identity issues of the developmental moment but also other issues (e.g., intimacy) that are foundational to successfully meeting other developmental challenges across the life span (Waterman, 1994).

According to Erikson, in order to engage in intimacy, one must have achieved a sense of identity. Intimacy is referred to as the ability to fuse one's identity with another person without fear of losing it. Intimacy also involves such concepts as mutual trust, sacrifice, compromise and commitment within a relationship (Erikson, 1968). 
"The essence of intimacy is the capacity to commit oneself to concrete affiliations and partnerships and to develop the ethical strength to abide by such commitments, even though they may call for significant sacrifices and compromises" (Erikson, 1950, p.237).

The relationship between identity and intimacy proposed by Erikson has been empirically supported. In researching the relationship between identity and intimacy in adolescents, Moore and Boldero (1991) found that adolescents with a resolved sense of identity reported having richer, more satisfying relationships. Mellor (1989) also found that adolescents with a resolved sense of identity reported their relationships as more connected as opposed to separate.

Like Raskin and Waterman (1994), this approach also views the relation between the tasks of identity and intimacy as bidirectional or reciprocal (i.e., that a positive identity resolution facilitates a sense of intimacy and that the process of developing a sense of intimacy fosters identity change). To Raskin and Waterman's view of the tasks of identity and intimacy as bidirectional, the co-constructivist approach adds the view of the process of resolving identity and intimacy issues as not only a potentially bidirectional process but also a potentially parallel process. That is, according to this coconstructivist approach, the process may take place bi-directionally (reciprocally or interactively), sequentially (with progress on identity issues preceding intimacy issue $o r$ intimacy issues preceding identity issues), or concurrently (progress in resolving both identity and intimacy issues taking place at the same time).

Exploration of Identity and Intimacy. Like Erikson $(1968,1980)$, the coconstructive approach considers psychosocially mature intimacy to be the capacity to 
commit oneself to an open, supportive, tender relationship without fear of losing one's own identity. To this view, the co-constructivist approach adds the view that the "capacity" for intimacy includes two components. The first is insight and understanding into the individual's own interpersonal needs; the second is awareness and sensitivity to the interpersonal needs of others. The co-constructivist approach considers the development of insight and understanding into one's own needs and awareness and sensitivity to the needs of others to enable the individual to commit her/him self to an intimate relationship. It is in this frame that the co-constructivist approach further considers "intimate" interpersonal relationships as a particularly important context for intimacy exploration as well as for identity exploration.

Exploration was the intervention strategy used to provide a context for individuals to increase their understanding of their own needs and an awareness of the needs of others. Beginning with the theoretical writings of Erikson $(1950,1982)$, the process of exploration has been viewed as central to the formation of an identity. Exploration is thus a process of examination and discovery of whom and what one might be. As such, exploration might be seen as a basic process underlying the formation of an identity (Berman, Schwartz, Berman, \& Kurtines, 2000/in press). This process of exploration provides a strategy for addressing identity issues as they emerge in the context of relationships. Exploration is a process of discovery, one that involves investigation, examination, and analysis. In this case, exploration was a process of discovery directed toward gaining insight into one's own needs and the needs of others.

Issues that arise in the context of intimate interpersonal relationships are an important setting for exploration. This is because exploration focuses directly on intimacy 
issues and such exploration fosters within the individual the development of insight and understanding into the individual's own interpersonal needs and the development of awareness and sensitivity to the interpersonal needs of others. In addition relationship issues that arise in the context of intimate relationships also provide the opportunity to explore core identity issues and, in the process, foster identity development.

Exploration for insight also helps the participant focus on the subjective process that is most essential to maintaining the affective foundation for intimate relationships, mutuality of involvement. Mutuality of involvement in intimate relationships is the shared emotional bond that forms between people who care about and know and understand each other in a special way. Mutuality of involvement includes: 1) the equality of the degree of the emotional bond that forms between participants in a relationshipboth participants are "equally" involved and 2) the degree to which the relationship meets the interpersonal needs of both participants and the degree that they are sensitive to each other's needs. If the participants in a relationship do not share a mutual affective involvement in their particular relationship and if the relationship does not meet their interpersonal needs, the relationship will not be experienced as an intimate one. The specific aspects that the workshop focused on are: 1) recognition of an imbalance in involvement in the relationship, 2) insight into and understanding of the individual's own interpersonal affective needs (e.g., trust, empathy, caring); and 3) insight, understanding and sensitivity to the interpersonal affective needs of others.

The co-constructivist approach also provides a framework for developing group interventions that use intimate relationships as a context for fostering the development of a sense of intimacy as well as identity. From such a perspective, relationship issues 
provide a useful context because different individuals in a group intervention may be at different points in the development of their capacity for intimacy as well as identity -- not only at different points with respect to others in the intervention, but also at different points with respect to their own personal development along these two dimensions. With respect to intimacy, in particular, variation in past relationship history, developmental stage, personal progress in resolving intimacy and identity issues, etc. may result in some people having a greater capacity for intimacy than others. That is, in having a greater understanding of their own needs and sensitivity to needs of others.

One of the goals of the intervention strategy described next is to use, at the group level, group discussion of relationship issues and, at an individual level, individual reflection on relationship issues as a context for encouraging the individual members of the group to use the process of exploration as a means for gaining greater insight and understanding into their own unique pattern of interpersonal needs (and how they acquired those needs) as well as awareness and sensitivity the interpersonal needs of others. This intervention strategy, therefore, explicitly targets intimacy issues while at the same time takes advantage of the same process of exploration to address identity issues as they emerge in this context. Issues that arise in the context of intimate interpersonal relationships may frequently serve to precipitate the exploration of identity issues by touching on the individual's basic life goals and values as well as the exploration of intimacy issues by touching on goals and values that are at the core of particular relationships. Intimate interpersonal relationships, according to this co-constructivist approach, often provide a context in which "powerful" affective states occur that set the 
"stage" for identity and intimacy exploration and changes in identity and intimacy commitment.

Individual and Group Level: Therapeutic Relationship and Group Affiliation

The co-constructivist approach's emphasis on the importance of the relationship of intervention participants to the facilitator and the group draws on the interpersonal theory of Sullivan (1954). According to Sullivan, the role of the therapist is one of "participant-observer", that is the therapist participates with the client in an interpersonal relationship, then observes the client's interpersonal skills. The therapist also tries to gain an insightful understanding into what the client is saying, as well as looking for patterns of communication between the therapist and the client. These interpersonal processes that occur between the individual and the facilitator during the individual's reflection on relationship issues provide an important context or opportunity for the facilitator to use interpretation as a strategy for facilitating exploration. Drawing on the interpersonal tradition, this opportunity to develop insight and sensitivity in the context of the therapeutic relationship is viewed as having the potential to transfer to relationships outside of the intervention. To this the co-constructivist adds the view that in the context of a group intervention, interpersonal processes that occur between the individual and the group during the group discussion of relationship issues also provide an important context or opportunity for the group, through the process of mutual disclosure, to facilitate exploration. That is, that the participants' affiliation with the intervention group (assuming that the group provides a cohesive, trusting, and caring context) provides an additional opportunity for the intervention participants to explore their own needs and the needs of others. 
Researchers interested in the dynamics within the therapeutic relationship have found support for Sullivan's theory. Henry, Schacht and Strupp (1990) examined clients' views about themselves after they had therapy with a therapist that made negative, controlling, and hostile statements. They found that these clients thought less of themselves and made more self-effacing remarks than clients who had therapists that made more positive statements. Harrist, Quintana, Strupp and Henry (1994) also examined the effects of therapists on clients' self-statements. Again they found that therapists who use more positive, helping, nurturing techniques, the clients are more positive, self-accepting and self-nourishing themselves. Furthermore, they found that clients who had these positive therapists also showed a greater overall improvement in psychosocial functioning.

The Application of Exploration in Intervention Work

The co-constructivist approach begins the exploration process within an already existing relationship. This is an important first step because the types of relationship issues that have emerged in this relationship not only provide a useful context for gaining some understanding of the type of need or needs that a particular relationship satisfies. This process also frequently provides the foundation for further exploration on the part of the individual to gain some insight into her/his general interpersonal needs.

The co-constructivist approach uses individual and group disclosures to facilitate this process. Disclosures reveal relationship issues that provide the opportunity to explore interpersonal needs. The emphasis of the process of exploration for the co-constructivist approach is to begin to get the individual to understand what they want out of that particular relationship in the present as well as in the future (i.e., which of their 
interpersonal needs -- or need -- the relationship satisfies, e.g., care, trust, loyalty,

concern, etc.). In this respect, the co-constructivist approach draws on the humanistic and existential traditions of Rogers and Maslow. Rogers (1959) believed that the therapist should provide the client with unconditional positive regard, empathy, and genuineness. Roger's notion of a need for positive regard had a profound influence on his development of therapeutic techniques. He believed that if these conditions were present, then the therapeutic process would take place on its own. Maslow's view of psychotherapy was similar to Roger's because he also believed that the interpersonal process was they key to a successful therapeutic relationship. He believed that through a warm loving relationship with the therapist the client would satisfy their needs for loving and belongingness and therefore be free to independently achieve ultimate psychological growth (Maslow, 1970).

Cramer $(1987 ; 1988 ; 1989 \& 1990)$ conducted a series of studies correlating the three conditions of a therapeutic relationship with self-esteem and friends possessing these qualities, relatives possessing these qualities, and romantic partners possessing these qualities. He consistently found that individuals reporting having close relationships with people who exhibited unconditional positive regard, genuineness, and empathy all had higher levels of self-esteem. The co-constructivist approach, consequently, may also incorporate techniques such as unconditional positive regard, empathy and genuineness consistent with keeping the focus of an intervention that is both past and present-oriented. The next section outlines a framework for the implementation of the intervention and facilitative strategies. 
Intervention: Promoting Youth Development Program (PYD)

In an early essay regarding troubled youth, Erikson (Erikson \& Erikson, 1957) foresaw the importance of intervening during adolescence in order to redirect the energies of young people toward productive styles of living and to prevent society's confirmation of and a young person's commitment to a socially marginalized identity. Today, the number of such youth is extraordinary high, particularly among those who already began life marginalized. Such youth tend to respond to their marginalization in ways (e.g., impulsiveness or immediatism, pretending not to care, keeping their pain inside themselves, or escaping through drug use) that further distance them from prosocial sources of support, making them among the most difficult populations to work with when they can be engaged into interventions, which in itself is a challenge.

Toward a Solution: School-based Group Interventions that Target Marginalized Youth

The intervention used in this study was the Promoting Youth Development (PYD) program. Promoting Youth Development is an ongoing program of research being conducted at the Adolescent and Adult Development Program, Child and Family Psychosocial Research Center, Florida International University. PYD is a school-based psycho-educational program that targets promoting positive development in disadvantaged urban high school youth vulnerable to multiple negative developmental outcomes (manual available upon request).

PYD works closely with the Academy for Community Education (ACE) in Coral Gables, Florida. ACE is an alternative high school aimed at dropout prevention. The students at ACE may not have met their academic potential in the regular school setting and may have had attendance, behavior or motivational problems in school, but do not 
have serious emotional or learning problems or a serious record of violence or dangerous behavior. ACE's mission is to,

"... educate potential dropouts and students who have already dropped out and returned to school. Our goals are to provide a stimulating, nurturing environment where educational excellence and the highest possible level of student learning constitute the norm and to prepare the students to become contributing citizens in a democratic society" (Academy for Community Education, 1998-1999, p. 1). The PYD has been implemented at ACE through the school guidance office as part of the school's ongoing counseling program. Because the school is an alternative high school, students participate in counseling groups through either self or counselor referral. The workshop formats available to them include anger management, relationship, making life choices, substance abuse, alternative lifestyles, etc. This program of research uses a pragmatic orientation in the development of psychosocial interventions. This pragmatic orientation seeks to expand our scientific understanding of the role of interpersonal relationships in identity formation and the development of a sense of intimacy, and to use this knowledge to develop effective methods for alleviating the distress and suffering that these developmental tasks sometimes present. This pragmatic orientation seeks to integrate and combine the most efficacious methods of prevention, assessment, and intervention of psychosocial research.

For this study, PYD was implemented in the relationship workshop format. This format built on the Building Better Relationships Workshop (BBRW) developed by Lorente (1998). The BBRW, as noted above, was designed to combine the most beneficial features of a group format with intervention strategies adapted from the 
cognitive-behavioral tradition (e.g., skills training) and from the interpersonal tradition (e.g., exploration for insight). Furthermore, as recommended in the literature, the Building Better Relationships Workshop was designed to target intimacy and identity development in high school adolescents (Archer, 1994; Montemayor, Adams, \& Gullotta, 1994; Montgomery \& Sorell, 1998). A basic working hypothesis of the Lorente (1998) study was that it is possible to develop effective interventions with middle adolescents that target both identity and intimacy issues. Thus, although the BBRW aims at fostering the development of basic relationship skills and attitudes (e.g., democratic communication, equal participation, etc.), these are viewed mainly as foundational. That is, they are important in themselves, but they are also important because they help to set the stage for the main focus of the BBRW, i.e., to promote the development of identity and intimacy.

\section{Implementing PYD in Relationship Groups}

The first section will discuss the approach to group process used in this intervention. The second section will describe the rationale and conceptualization of the three intervention strategies -- skills and knowledge development training, experiential group exercises, and exploration enhancement. Although the components of the PYD intervention will be described separately in this proposal for purposes of explanation, they are conceptually interrelated and integrated in actual implementation.

\section{Group Process}

Freire's Transformative Pedagogy. For its intervention strategies, the PYD draws on Freire's (1983/1970) approach to empowering people by promoting the opportunity to enhance their critical consciousness about their exclusion from the mainstream. Freire 
developed this approach in his work with impoverished Brazilian peasants. He found that individuals who are marginalized by such extreme poverty have difficulty progressing through the classic classroom format. In Pedagogy of the Oppressed, Freire offered an alternative: a "problem posing" and participatory learning model. Freire referred to such a transformative pedagogy as a pedagogy of dialogue rather than instruction. Students take an active role and the interventionist (facilitator, teacher, etc.) works with the students in collaboratively identifying problems, creating and constructing alternatives, and taking action. In transformative pedagogy, youth not only talk about their problems, they do something about them. While intentionally identifying problems and following through by engaging in transformative activities to solve these problems, students become the experts and, in the process, develop a greater sense of control and responsibility over their lives. As a consequence of such mastery experiences, participants come to acquire a greater critical understanding, transform their sense of control and responsibility, and increase their proactive participation in defining who they are and what they believe in. We have found Freire's approach to be culturally and contextually appropriate, and very useful in the development of school-based interventions, because the concept of marginalization is a theme common to diverse populations, particularly troubled urban minority youth, a population that tends to be highly marginalized and extremely difficult to engage into interventions, to say nothing of working with to achieve positive results.

\section{Intervention Strategies}

The multifaceted format of PYD used three intervention strategies drawn from both the cognitive behavioral tradition and the interpersonal tradition: 1) skills and knowledge development training; 2) experiential group exercises, and 3) exploration 
enhancement. These intervention strategies were used to increase content knowledge about relationship issues and to use relationship issues to foster exploration of identity and intimacy issues. More specifically, at the content level, skills and knowledge development training in the context of relationship issues were utilized to increase the development of knowledge about relationship issues and in this way increase participants' relationship skills and foster positive attitudes and values with respect to the content areas (e.g., quality of communication, the equality of participation, the mutuality of involvement, etc.). At the process level, PYD used the remaining two intervention strategies to focus on fostering the exploration of intimacy and identity issues as they take place in the context of intimate relationships. The experiential group exercises were used to raise relationship issues that touch on quality of communication and equality of participation in relationships. The intervention strategy of exploration enhancement was used to raise relationship issues that touch on the mutuality of involvement and intimacy in relationships. In implementing these intervention strategies, the primary goal was to use the strategies as a context for identifying and addressing relevant intimacy and identity issues.

Skills and Knowledge Development Training. The first intervention strategy used in the workshop, skills and knowledge development, targeted the development of content knowledge. In earlier phases of the PYD, this procedure was implemented through the use of didactic classroom-type presentations. More recent phases have adapted this procedure to be more interactive, rendering it more engaging for this younger population. The presentations were conducted during the initial phase of introduction of each of the workshop sessions. The skills and knowledge development 
component provided each participant with an introduction to and an understanding of the concepts and constructs associated with the intervention, (e.g., communication, participation, and involvement). The utility of skills and knowledge development training has been documented in a variety of settings with diverse populations (Camp \& Bash, 1985; Spivack, Platt, \& Shure, 1976; Spivack \& Shure, 1982).

Experiential Group Exercises. The second intervention strategy in the PYD, experiential group exercises, also targeted content knowledge. Experiential group exercises have long been recognized as useful intervention strategies in the group process literature (Corey, 1997). At the content level, the group exercises targeted both communication and participation issues. More specifically, the group exercises were designed to increase the participants' awareness of the importance of open communication and equal participation in relationships. The group exercises were organized around a series of dilemmas. The content of the dilemmas was designed to raise both identity and intimacy issues, and range from personal dilemmas and relational dilemmas to moral dilemmas. In the PYD participants were encouraged to offer their own real life dilemmas as well, in order to render the exercises more engaging. For the experiential exercises, the members of the group engaged in dialogue over the dilemmas and were encouraged to identify and discuss intimacy and identity issues that emerge out of the dialogues.

\section{Fostering Open Communication and Constructive Conflict}

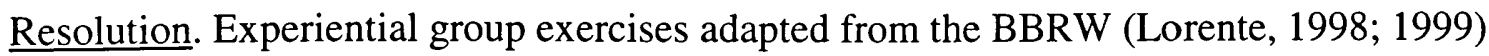
were used to raise the issue of open communication and constructive conflict resolution in relationships. The form of communicative exercises for this intervention drew upon 
previous work that has been done in the area of communication (Habermas, 1979;

Samuels \& Samuels, 1975) and included exercises that target the development of two critical communicative skills. The first of these critical communicative skills included developing the capacity to recognize the use of strategic actions in communication (i.e., the use of force, power, intimidation, manipulation, deception, etc.), and developing ways of dealing with the use of such actions. The second included the use of critical discussion in the resolution of conflict. This exercise stressed critical problem solving through a process of generating alternatives, suspending judgement and critically evaluating the alternatives. The discussions of communication in relationships were used as a context for participants to work on identifying and discussing intimacy and identity issues that emerged out of the exercises and out of their own personal dilemmas.

Fostering Equal Participation in Relationships. Experiential group exercises were also used to raise the issue of equal participation in relationships. The coconstructivist approach asserts that the balance of power in a relationship is important. There is evidence that individuals are happier if both members of the pair contribute equally to the decision-making (Peplau \& Campbell, 1989). Equal participation implies that neither person is excluded from participation in the decision-making process, and that the needs, interests, goals, and values of both persons are included in the decision-making processes. The discussions of participation in relationships are used as a context for participants to work on identifying and discussing intimacy and identity issues that emerge out of the exercises.

Exploration Enhancement. In conceptualizing, operationalizing, and implementing exploration as an intervention strategy, the co-constructivist approach 
draws on the psychosocial development tradition. Beginning with the theoretical writings of Erikson $(1950,1986)$, this tradition has viewed exploration as central to the process of psychosoical development in general and the development of identity and intimacy in particular. The recognition of the importance of exploration, for example, is evident in the considerable empirical work (e.g., Grotevant \& Cooper, 1981; Marcia \& Archer, 1993) generated by Marcia's $(1966,1980)$ pioneering work on the identity status paradigm. Recent work has begun to articulate more fully the components of the exploration process. Grotevant (1987), for example, has proposed a process model for understanding psychosocial development in which the important components of the process may be defined as "problem-solving behavior aimed at eliciting information about oneself or one's environment in order to make a decision about an important life choice" (p. 204). Moreover, Grotevant's process model includes, "those abilities and orientations that individuals bring to bear on the identity formation process"(pp. 204-205). Drawing on this work, the co-constructivist approach uses exploration in helping participants to gain insight into and understanding of the unique combination and strength of their interpersonal needs (i.e., their "pattern" of needs) and why they have that special or unique pattern of needs (i.e., the unique "pathway" by which they came to have these needs). Exploration is a process of discovery, one that involves investigation, examination, and analysis. In this case, exploration is a process of discovery directed toward gaining insight into one's own needs and the needs of others.

The co-constructivist approach uses disclosure to "facilitate" the exploration process, and implements the intervention and facilitative strategies at two levels, group and individual. At the group level, the process of exploration takes the form of group 
discussion of relationship issues and involves the participant's affiliation with the group. At the individual level, in contrast, the process of exploration takes the form of individual reflection on relationship issues and involves the participant's therapeutic relationship with the group facilitator.

The co-constructivist approach thus provided a framework for the use of skills and knowledge development training and exploration enhancement as intervention strategies for increasing individuals' acquisition of relationship skills and the exploration of their own needs and an awareness of the needs of others. Thus, in addition to evaluating the impact of therapeutic relationship processes using the relationship impact subscales of the SEF (Group Impact and Facilitator Impact), this study also evaluated the impact of relationship skills and knowledge development training and exploration enhancement using the task impact subscales of the SEF (Skills Impact and Exploration Impact).

\section{METHODOLOGY}

\section{The Current Study}

This study was conducted to investigate the feasibility of using a session impact measure (the SEF) with a difficult to work with population of adolescents in a schoolbased setting and on the utility of the SEF as a measure of Group Impact, Facilitator Impact, Skills Impact, and Exploration Impact as markers of therapy process. This included extending and refining a measure developed in the adult literature. The measure that was developed was designed to provide a method for assessing the impact of therapy process on a session-by-session basis in adolescent group interventions. In this context, the goal was to conduct a preliminary feasibility study in a field setting to evaluate the appropriateness of the measure. This included pilot-testing and refining procedures for 
administering the measure in the group interventions on a session-by-session basis and procedures for scoring the evaluations across sessions. A further goal of this study was to collect some initial baseline data with respect to the measure's capacity to assess the differential impact of process across intervention groups within the sample. A final goal was to begin to explore, in a preliminary way, the impact of therapy process in the groups (as assessed session by session) on intervention outcome by drawing on an ongoing school-based intervention that targets promoting positive development in at-risk adolescents in an ethnically diverse context. To accomplish these goals, the project drew on the program of research described above in implementing a study that explored the relationship between the impact of therapy processes and the outcome. The study addressed three main research questions.

First research question. The focus of the first research question was on evaluating the feasibility of using a session impact measure with a difficult to work with population of adolescents in a school-based setting. Qualitative analyses were used to evaluate the appropriateness of the measure as well as to pilot-test and refine procedures for administering the measure in the group interventions on a session-by-session basis.

Second research question. The second research question concerned the utility of the SEF as a session impact measure of therapy process. More specifically, it focused on the capacity of the SEF to assess the differential impact of process across the intervention groups within the sample. This question was thus concerned with the degree to which the measure was capable of assessing a difference among the groups in the impact of therapy processes. The impact of these therapy processes such as therapeutic relationships and intervention tasks and activities were assessed by the subscales of the SEF on a session- 
by-session basis. The Group Impact and Facilitator Impact subscales were used as markers of group support, group cohesion, and therapist support and the Skills Impact and Exploration Impact subscales were used as markers of skills acquisition and personal exploration.

Third research question. The third research question also concerned the utility of the SEF as a session impact measure of the therapy process. This research question, however, focused on the utility of the SEF as a measure of the impact of therapy process in the groups (as assessed session by session) on the intervention outcome (pre to post) including the developmental processes postulated to be related to promoting identity and intimacy development. This research question thus investigated, in a preliminary way, the links between differential impact and the outcome targeted by the intervention (i.e., intervention domains). More specifically, it was expected that positive perceptions of the session impact of therapeutic processes as measured by the SEF four subscales (Group Impact, Facilitator Impact, Skills Impact, and Exploration Impact) would be related to improvement on the outcome measures and that negative perceptions of session impact would be related to deterioration on the outcome measures.

The investigation into the impact of therapeutic processes in interventions that target identity and intimacy opens up substantial potential for the development of knowledge which has considerable theoretical, empirical, and practical significance.

\section{$\underline{\text { Participants }}$}

A total of 31 middle adolescent high school students from Miami-Dade County Public Schools participated in this study. Participants in this study consisted of urban youth who were identified by Dade County Public Schools as "at risk" for a multitude of 
problem behaviors and adverse outcomes. This study sample was drawn from the Academy for Community Education (ACE). The sample included 13 males and 18 females with a mean age of 16.61 . The sample was multiethnic, with the two largest ethnic groups being African American (45\%) and Hispanic (32\%) with a smaller proportion describing themselves as Bi-Ethnic (13\%) and White Non-Hispanic (10\%). Although the initial number of participants was 31 , only 27 of the participants completed the process measures and only a total of 24 participants completed the outcome measures.

Participant Recruitment and Selection. Participants were obtained through self or counselor referrals. Students not participating in the study were able to participate in other workshop formats. In addition, any student not selected for participation (or who chose not to participate in the study during a given semester) was eligible to participate in alternative workshops during that semester and/or one of the intervention conditions the following semester.

Procedure

The participants were randomly divided into three intervention groups with the same structure and format and with three different group facilitators. At the beginning of the study, Group 1 had 11 participants, Group 2 had 10 participants, and Group 3 had 10 participants. A total of seven participants were not included in the final analysis of the study. Participant attrition was fairly evenly distributed across the groups. There were 3 participants who were excluded because they were not able to complete all of the outcome measures due to a lack of attendance at school during the post assessment sessions. There were 4 participants who were excluded because they stopped attending the groups for reasons such as dropping out of school (2) and being pulled out of the 
groups due to poor grades in class (2). At the end of the study, all 3 groups had 8

members each who had completed both the process measures and the outcome measures and could be included in the analysis.

The group facilitators were three graduate level students between 23 and 30 years of age with differing levels of previous experience conducting group interventions. Group 1 Facilitator, the most experienced, was a White female who had conducted a number of previous relationship groups as well as other groups, and served as coordinator for the relationship groups. Group 2 Facilitator was a Hispanic female who had experience in conducting both relationship groups and other types of groups (anger management, abuse, etc.). Group 3 Facilitator was a White female who had experience in conducting other types of groups (anger management, children of alcoholics, etc.) but had not previously conducted relationship groups. During the spring semester, the groups met once a week for 10 weeks for a duration of 45 minutes. All participants were pre- and post-tested on measures of identity, intimacy and interpersonal relationship components. The SEF was administered at the end of every session in all groups by a group assistant.

\section{$\underline{\text { Measures }}$}

The measures described in this section were selected to assess both process and outcome. The study included a quantitative measure of the impact of four domains of therapy processes on intervention sessions (see Appendix). The impact measure was administered at the completion of every session (i.e., on a session by session basis). In order to reduce response bias, the session evaluation form was administered by the group assistant while the group facilitator left the room. In addition, the study included two measures tapping domains identified as relevant to identity development, two measures 
identified as relevant to intimacy development, and a measure of internalizing behavior problems. In order to ease participant burden, the measures were combined into 3 packets; the first packet contained the CPSS and was administered in interview format, the second packet contained the EPSI, the EIPQ and the Youth Report Form questions, and the third packet contained the RAVS.

$\underline{\text { Intervention Impact Measure }}$

Therapeutic Process Measure. The Session Evaluation Form (SEF; Bussell \& Kurtines, 1999) is the session impact measure reported in this study that was adapted from the Session Impact Scale (Elliot \& Wexler, 1994) and consisted of four main subscales. The first two subscales, Group Impact (4 items) and Facilitator Impact (2 items) assess the impacts of the therapeutic relationship between the group and the participant and the facilitator and the participant, respectively, during the session. The third and fourth subscales were adapted to assess the impact of intervention specific content. The third subscale, Skills Impact ( 2 items), assesses the effects of the session on the participants' perception of skills acquisition. The fourth subscale, Exploration Impact ( 2 items), assesses the impact of the session on the participants' personal exploration. These impact items were tailored to be specific to our population, and the facilitative strategies used in the intervention, specifically knowledge development and exploration enhancement. All items were rated on a 5-point Likert scale $(1=$ not at all, $2=$ slightly, 3 $=$ somewhat, $4=$ pretty much, and $5=$ very much). Internal reliability coefficients (Cronbach's alpha) for the SEF subscales were Group Impact, $r=.94$; Facilitator Impact, $\mathrm{r}=.93 ;$ Skills Impact, $\mathrm{r}=.93$ and Exploration Impact $\mathrm{r}=.89$. The internal reliability coefficient (Cronbach's alpha) for the SEF Overall Impact was $r=.97$. 
$\underline{\text { Intervention Outcome Measures }}$

Cognitive Skills and Knowledge. The Critical Problem Solving Scale (CPSS;

Berman, Schwartz, Kurtines, \& Berman, 2000/in press) is a performance-based measure of critical problem solving and decision making that has been shown to be related to identity exploration. The CPSS assesses participants' capacity to generate alternatives to one hypothetical dilemma and one personal dilemma, to cognitively decenter and evaluate each alternative, and to select the alternative supported by the 'best argument.' Accordingly, the CPSS yields four scores: the Generation of Alternative Solutions (GA) score is the average number of choices generated across both dilemmas, the Decentering Positive Alternatives (DPA) and the Decentering Negative Alternatives (DNA) scores consist of the average number of "cons" provided for the participant's own "best" alternatives and the number of "pros" provided for the participant's own "worst" alternatives, respectively, across the two dilemmas, and the Modification (MO) score is an index of participants' willingness to modify their original "best" choices ( 0 for no modification, 1 for modification without reasoning, and 2 for modification with reasoning), across the two dilemmas. The CPSS Total Score (CPSSTOT) is the average of all of the scale scores $((\mathrm{GA}+\mathrm{DPA}+\mathrm{DNA}+\mathrm{MO}) / 4)$ and provides an overall index of performance on the CPSS as a whole. The CPSS responses were scored by raters trained in using the CPSS codes. Interrater reliability for the scoring codes has been reported as 89 percent, and Cronbach's alphas for the CPSS Total Score are .68 for high school students and .70 for college students. The test-retest reliability for the CPSS Total Score is .85 for high school students (Sosa-Biziack et al., 1999). 
Relationship Attitudes and Values. The Relationship Attitudes and Values Scale (RAVS): The RAVS (Lorente \& Adams, 1998) was used to assess the impact of the intervention on relationship skills. The RAVS is a 20 -item self-report questionnaire rated on a 5-point Likert scale that is designed to assess individuals' attitudes toward components of interpersonal relationships (quality communication, equal participation, mutuality of involvement, and a total relationship component value score) and yields four quantitative scores. The first two scores tap the participant's attitude toward and value of the two types of relationship skills that were targeted, communication and participation. The third score, mutuality of involvement, taps the participant's attitude toward and value of exploration and mutuality as it relates to intimacy. Scores in each of the areas (Communication, Participation, and Involvement) were obtained by summing the participant's ratings of the overall content area resulting in a minimum score of 6 and a maximum score of 35 for each content area. The total score is an overall total score of the ratings for each content area thus resulting in a minimum score of 20 and a maximum score of 100. Internal reliability coefficients (Cronbach's alpha) for the RAVS, as reported by Lorente \& Adams (1998) were $r=.80$. Test-retest reliabilities were not reported.

Intimacy. Erikson's Psychosocial Stage Inventory (EPSI) was used to assess the impact of the intervention on intimacy versus isolation. The EPSI (Rosenthal, Gurney, \& Moore, 1981) is a 72-item measure that includes six subscales corresponding to Erikson's first six stages of psychosocial development. For the purposes of this study only the intimacy subscale was used. The intimacy subscale is a 12-item self-report survey rated on a 5-point Likert scale with six items representing successful and six items representing 
unsuccessful resolution of the intimacy versus isolation crisis. Items were developed by utilizing key words and statements from Erikson's characterizations of the stages. These items were screened for ambiguity and face validity by the authors and were simplified as much as possible. The measure was designed for use with a sample that was age 13 or above. Responses are made according to a Likert scale ranging from hardly ever true (1) to almost always true (5). This subscale of this measure yields a minimum score of 12 and a maximum score of 60 . The EPSI can be administered individually or in a group format. Rosenthal et al. (1981) reported the reliability and validity of this measure using a high school sample of 622 adolescents. They reported an alpha $=.63$ for the intimacy subscale, as well as satisfactory construct validity. Construct validity was established by comparing EPSI scores to scores obtained on the PSM. Greenberger and Sorensen developed the PSM in 1973 as a self-report attitude inventory designed to measure psychosocial maturity. Conceptual links between the two measures were said to be strong enough to predict relationships between the subscales of each of the measures. Accordingly, there were "encouragingly high correlations with relevant subscales of the PSM, providing some measure of construct validity" (Rosenthal et al., 1981, p.531).

Identity Exploration and Commitment. The Ego Identity Process Questionnaire (EIPQ; Balistreri, et al. 1995) was used to assess identity exploration and commitment. The EIPQ is a 32-item self-report survey that uses a 5-point Likert scale. Scores for exploration and commitment are determined in both ideological (i.e., politics, religion, occupation, and values) and interpersonal (i.e., friendships, dating, gender roles, and family) life domains. The EIPQ contains scales for exploration (Alpha .76, Test-retest 
.91 ) and commitment (Alpha .75, Test-retest .76). Both scales can be subdivided into ideological and interpersonal content domains.

\section{Additional Outcome Measure}

Internalizing Behavior Problem Measure. The Child Behavior Checklist, Youth Self-Report (YSR; Achenbach, 1991) was used to assess internalizing problem behaviors. The CBCL, on which the YSR is based, is a widely used measure of child and adolescent problem behaviors. The Youth Self-Report (YSR) is a self-report measure appropriate for use with individuals between the ages of 11 and 18 (Achenbach, 1991). The YSR can be scored for internalizing, externalizing, and total behavior problems. For this study, selfreports of depression and social withdrawal from the internalizing scales were obtained. There were 8 items that described symptoms of depression and 8 items that described symptoms of social withdrawal. Participants rated how true each item was at present or within the past 6 months using the following scale: $0=$ not true (as far as you know); 1 =somewhat or sometimes true; $2=$ very true or often true. Achenbach (1991) has reported a test-retest correlation of .80 for internalizing self-reported behavior.

\section{RESULTS}

This section presents initial baseline data obtained from the use of the SEF with the sample used in this study. Because this study was exploratory in nature, it included both a quantitative and qualitative component. The analyses reported in this section were intended to provide a preliminary evaluation of the utility of the SEF measure as well as to provide guidelines and directions for future development and refinement of impact measures with this population. The analyses also began to explore the impact of therapeutic processes and their relationship to intervention outcome. The results of this 
study are viewed as tentative and will serve to provide the groundwork for further investigations into treatment-process variables in group interventions.

Group comparability

Comparisons of the sociodemographic variables and the outcome measures at pretest were examined across groups using ANOVAs. No significant differences were found.

\section{First Research Question}

The first research question concerned evaluating the feasibility of using a session impact measure with a sample of adolescents in a school-based setting. Qualitative analyses were used to evaluate the appropriateness of the measure as well as to pilot-test and refine procedures for administering the measure in the group interventions on a session-by-session basis.

Research Question 1.: Will the format of the SEF be easy for the PYD participants to understand and to use?

Before administering the SEF as part of this study, it was pilot tested in relationship groups that were run at ACE during the previous semester. Throughout the pilot testing, several aspects of the SEF were examined and modified as a result of feedback from group participants. The first of the modifications involved changing the wording of the instructions to include the word "group" instead of "session". The participants indicated that they had difficulty understanding the meaning of the word "session" and that they preferred using the word "group". Although the measure is called the Session Evaluation Form, the measure almost always uses the word group. 
The second modification involved changing the format of the SEF. The original format was in a portrait orientation which caused many of the statements to take more than one line and caused the Likert scale responses to be spaced very close together. Feedback from the participants indicated that the form was a lot of "work" to fill out for every session. In order to make the measure look less cumbersome and to be easier to complete, it was modified to a landscape orientation with one statement per line and more space for the Likert scale choices.

The final modifications involved the administration of the SEF. Many of the responses were obtaining a ceiling effect, that is the participants would circle "Strongly Agree" (5) for all of the statements. After interviewing the participants, it was found that the reasons for this were twofold, the first was that they were not taking the form seriously and the second was that they were concerned about the leader reading their responses. As a result of this feedback, it was decided that the group facilitator would leave the room while the group assistant would explain the questionnaire and go over each statement as he or she would monitor each participant's progress in filling out the form. It was emphasized that this must be done upon every administration.

The overall result of these modifications was that the SEF was easier to administer. As a result of the word change and the format change, there were no problems during the study with comprehension or utilization of the SEF and no refusals to fill out the form. As a result of the change in administration, the participants were able to stay task-oriented and as indicated by the results below, there was less of a problem with the ceiling effect. 


\section{$\underline{\text { Second Research Question }}$}

The second research question concerned the capacity of the SEF to assess the differential impact of process across intervention groups within the study sample. This research question focused on the utility of the SEF as a measure of session impact. More specifically, this question was concerned with the degree to which the measure was capable of assessing the difference among the groups in the impact of therapy processes such as therapeutic relationships (i.e., group support, therapist support) and therapeutic tasks and activities (i.e., skills acquisition, personal exploration) during group sessions. One-way ANOVAs (with 3 levels) were used to evaluate between group differences in the impact of therapy process across the intervention groups. Although constrained by the limited statistical power of the sample size, the results of the one-way ANOVAs tended to provide support for a differential impact on therapy process across groups. These results are, however, clearly viewed as tentative and exploratory.

Research Question 2: Will the sessions within each group have a differential impact on the group participants' perception of the therapy process across the groups?

Hypothesis 2.a: There will be a differential impact on therapeutic relationships across the groups as measured by the SEF Group Impact and Facilitator Impact subscales.

Hypothesis 2.b: There will be a differential impact on and intervention tasks and activities across the groups as measured by the SEF Skills Impact and Exploration Impact subscales.

The statistical analyses used to test Hypothesis 2.a and 2.b consisted of one-way Analyses of Variance. The analyses were specified as a between-subjects design where Group $(1,2$, or 3$)$ was the between group factor. 
The dependent variables for Hypothesis 2. a consisted of the Group Impact and Facilitator Impact subscales of the SEF averaged across all 10 sessions. The ANOVA yielded a significant effect for Facilitator Impact, $F(2,23)=3.69, \mathrm{p}=.042$, but not for Group Impact. Group Impact approached significance, $F(2,23)=3.20, p=.061$. Because this trend approached significance, Group Impact (4 items) was further examined by dividing it into component parts, Group Cohesion (2 items) and Group Support (2 items). The ANOVA for Group Cohesion was not significant, however, the analysis was significant for Group Support, $F(2,23)=3.43, \mathrm{p}=.05$.

The dependent variables for Hypothesis 2.b consisted of the Skills Impact and Exploration Impact subscales of the SEF averaged across all 10 sessions. The analyses yielded a significant effect for Skills Impact, $\mathrm{F}(2,23)=3.58, \mathrm{p}=.047$ and it yielded the largest significant difference for Exploration Impact $F(2,23)=4.30, p=.027$. An additional ANOVA conducted using Overall Impact (the average score across all scales) was also found to be significant, $\mathrm{F}(2,23)=3.92, \mathrm{p}=.036$. Means, standard deviations, and F- ratios for Groups 1, 2, and 3 on the scales of the SEF are presented in Table 1.

The means in table 1 indicate that the average response to the sessions were positive, falling in the "slightly agree" or "strongly agree" categories. This result is due to the fact that the subscales were averaged across all 10 sessions for the analysis. Although the means are high, a visual inspection of the individual responses indicated that Group 3 had far more "neutral", "slightly disagree", and "strongly disagree" ratings than Group 1 or Group 2. It is also important to note that Group 1 and Group 2 did not receive any “strongly disagree' ratings on any of the Session Evaluation Forms. 
Table 1.

Means(Standard Deviations)' and F Values for

Groups 1, 2 and 3 on the SEF Subscales.

\begin{tabular}{c|c|c|c|c} 
Subscale & Group 1 & Group 2 & Group 3 & F Ratio \\
\hline \hline Group Impact & $4.713(.4819)$ & $4.512(.2919)$ & $4.135(.5716)$ & 3.20 \\
Group Cohesion & $4.783(.3756)$ & $4.647(.2977)$ & $4.300(.5922)$ & 2.57 \\
Group Support & $4.643(.5993)$ & $4.377(.3205)$ & $3.970(.5830)$ & $3.43^{*}$ \\
Facilitator Impact & $4.638(.4719)$ & $4.739(.1828)$ & $4.138(.6469)$ & $3.69^{*}$ \\
Skills Impact & $4.698(.4718)$ & $4.428(.3411)$ & $3.981(.7405)$ & $3.55^{*}$ \\
Exploration Impact & $4.737(.3709)$ & $4.330(.5132)$ & $3.969(.6498)$ & $4.30^{*}$ \\
\cline { 2 - 5 } Overall Impact & $4.693(.4410)$ & $4.504(.2829)$ & $4.071(.5095)$ & $3.92^{*}$ \\
\hline \hline
\end{tabular}

*The mean difference is significant at the .05 level.

Post Hoc analyses using the LSD test for all of the scales showing significant differences indicated that there were significant differences between Groups 1 and 3 for Group Support, Facilitator Impact, Skills Impact, Exploration Impact, and Overall Impact. There was also a significant difference for Facilitator Impact for Groups 1 and 2, however there were no other significant differences between Group 1 and 2 and no significant differences between Group 2 and 3.

\section{Third Research Question}

The third research question also concerned the utility of the SEF as a measure of the impact of therapy process. This research question, however, focused on the relationship of the impact of therapy process as it takes place in sessions and on intervention outcome. That is, this research question investigated, in a preliminary way, the links between differential session impact and the effects of the group intervention (pre 
to post) on the developmental processes postulated to be related to promoting identity and intimacy development. The third research question thus concerned the main effects of the intervention and their interaction with the impact of group processes.

Research Question 3: Will the intervention have a positive impact (pre to post) as measured by the outcome measures and will this effect differ by groups?

Hypothesis 3.a: The intervention will significantly increase identity and intimacy development on the CPSS, RAVS, EPSI, EIPQ and significantly reduce depression and social withdrawal on the Youth report Form.

Hypothesis 3.b: There will be differential change (pre to post) across the intervention groups on the CPSS, RAVS, EPSI, EIPQ and depression and social withdrawal on the Youth report Form.

Hypotheses 3.a and 3.b were tested with a 2 X 3 mixed design (within and between) repeated measures ANOVAs (Time [pre-post] as the within X Group [1, 2, 3] as the between) were used to test for main and interaction effects on the outcome measures. The $2 \times 3$ mixed designed ANOVAs indicated that there were no significant effects for Time, Group, or Group by Time interactions for any of the outcome variables.

\section{Exploratory Analyses}

A visual examination of the cell means for the ANOVAs, however, suggested that there was change from pre to post and that these changes were in the expected direction, although these trends did not achieve statistical significance. This may have been due to the fact that for these analyses the use of a more complex 2 X 3 mixed design ANOVA (in contrast to the simple one-way ANOVA used in the previous analyses) with such a small sample ( 8 participants per group ) departs from the assumptions required by 
parametric analyses such as ANOVAs for these types of analyses.

A visual examination of the trends in the data also suggested the level of the significance of the main effect due to pre to post test changes may have been moderated by intervention group. Moreover, the direction of these trends was consistent with the findings from Hypothesis 2, namely, that there were significant differences for all the process variables (including Overall Impact) between Groups 1 and 3. More specifically, the outcome results tended to follow the same pattern observed with the process variables, with Group 1 (the group with the highest ratings on the SEF ) tending to change in the improvement direction on the measures and Group 3 (the group with the lowest ratings on the SEF ) tending either not to change or in some cases deteriorate. Further, the pattern of change (Group 1 improving and Group 3 staying the same or deteriorating) was consistent across a number of variables.

In view of the consistency of these patterns and the possibility that these trends did not appear as a significant Time by Group interaction because distribution assumptions were not met for the ANOVAs, it appeared useful to further investigate differential effects of therapy process as a possible moderator of intervention outcome using distribution free statistical analyses.

Subsequent analyses were conducted using nonparametric tests (i.e., Chi square two-way contingency tables) in order to provide a more appropriate test of these trends. For the purpose of testing for group differences in pre to post change on the CPSS, RAVS, EPSI, and Youth Report Form using Chi square analyses, participants in the three groups were classified into three change categories: Improve, any change in the measures in a positive direction from pre to post; $\underline{\text { Same }}$, no change in measures from pre to post; 
Deteriorate, any change in the measures in a negative direction from pre to post. The change scores ranged from -1 to 1 on the CPSS, from -12 to 13 on the RAVS, from -13 to 10 on the EPSI, and from -9 to 4 on the CBCL. The Chi square analyses were conducted using only those in the Improve and Deteriorate categories. Due to the small range on change scores for the CPSS, it was not included in the exploratory analysis. The Chi square analyses for the EIPQ was conducted using increases and decreases in exploration and commitment. The change scores ranged from -15 to 12 on the exploration subscale of the EIPQ and -24 to 16 on the commitment subscale of the EIPQ. The results of these two-way contingency table analyses provided support for the moderating effects of group on several outcome measures.

Exploratory Hypothesis 1.a: There will be a significant difference between intervention Groups 1 and 3 in increasing the participants' communication quality, equality of participation in relationships, and intimacy exploration as measured by the mutuality of involvement subscale on the RAVS.

Hypothesis 1.a was tested using a Chi square test of a two-way contingency table (Group $=1$ or 3, Outcome=improve or deteriorate). Results of the Chi square analysis for the scores on the RAVS were not significant.

Exploratory Hypothesis 1.b: There will be a significant difference between intervention Groups 1 and 3 in increasing the participants' successful resolution of the intimacy versus isolation crisis as measured by the EPSI.

Hypothesis 1.b. was tested using a Chi square test of a two-way contingency table (Group $=1$ or 3, Outcome=improve or deteriorate). Results of the Chi square with Fisher's Exact test for outcome on the EPSI Interpersonal scale indicated that Group 1 participants 
who changed moved significantly more in the "improved" direction than the participants in Group 3, $\chi^{2}=(1 \underline{\mathrm{N}}=14)=5.60, \underline{p}=.035$. As can be seen from Figure 1 , whereas all participants in Group 1 either improved or stayed the same, in Group 3 more participants deteriorated than improved.

\section{EPSI: Interpersonal Score}

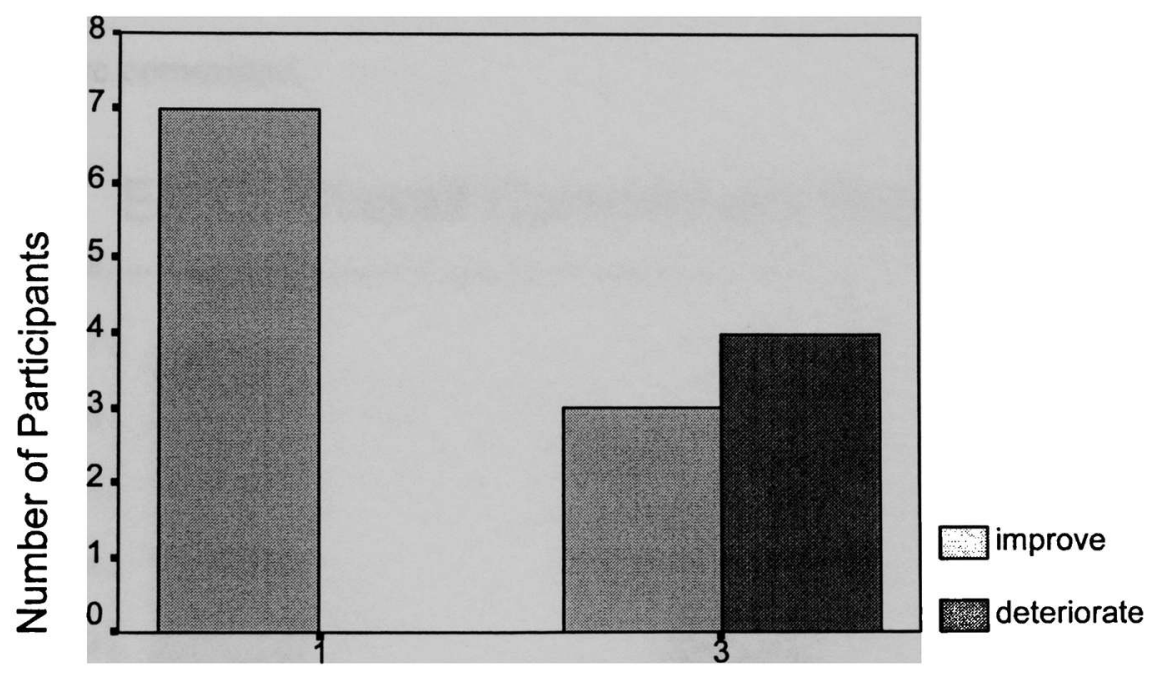

Group Number

Figure 1. Chi Square Results for the EPSI: Interpersonal Score

Exploratory Hypothesis 1.c: There will be a significant difference between intervention Groups 1 and 3 in increasing the participants' identity exploration and commitment as measured by the EIPQ scales.

Hypothesis 1.c was tested using a Chi square test of a two-way contingency table (Group $=1$ or 3 , Outcome $=$ more commitment or less commitment, more exploration or less exploration). The results of the Chi square with Fisher's Exact test for outcome on 
the EIPQ exploration scale were not significant, but the results for the commitment scale indicated that Group 1 participants who changed moved significantly more in the "more commitment" direction than the participants in Group 3, $\chi^{2}(1 \underline{\mathrm{N}}=14)=7.03, \underline{p}=.016$. The Chi square analysis did not reveal significant changes for any of the other EIPQ scales. As can be seen from Figure 2, whereas almost all participants in Group 1 became more committed vs. less committed, in Group 3 almost all participants became less committed vs. more committed.

\section{EIPQ: Overall Commitment Score}

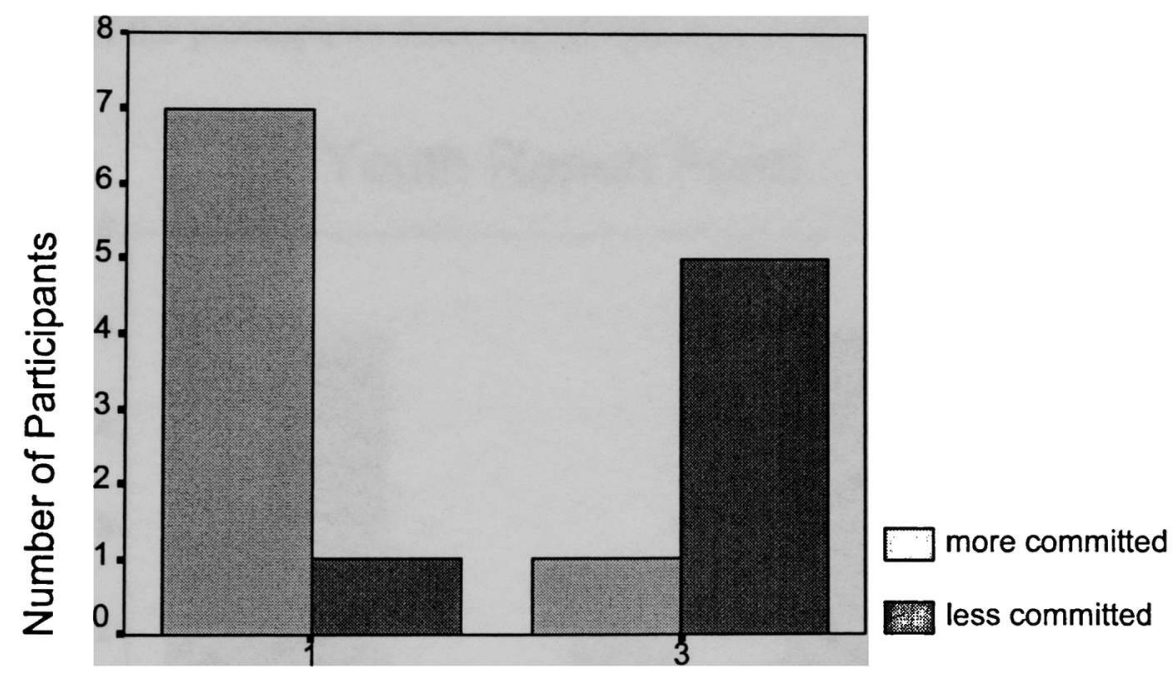

Group Number

Figure 2. Chi Square Results for the EIPQ: Commitment Score

Exploratory Hypothesis 1.d: There will be a significant difference between intervention Groups 1 and 3 in decreasing the participants' depression and social withdrawal as measured by the Youth Report Form. 
Hypothesis 1.d was tested using a Chi square test of a two-way contingency table (Group $=1$ or 3, Outcome=improve or deteriorate). Results of the Chi square with Fisher's Exact test revealed that although outcome on the Youth Report Form was not significantly related to group membership, the analysis did approach significance $\chi^{2}=(1$ $\underline{\mathrm{N}}=10)=4.29, \underline{\mathrm{p}}=.083$. This result could be due to the fact that many participants in Group 1 stayed the same and the "same' category was excluded from the analysis. However, Figure 3 clearly shows that none of the participants in Group 1 fell into the "deteriorate" category and they either improved or stayed the same, whereas in Group 3 a larger proportion of the participants deteriorated than improved or stayed the same.

\section{Youth Report Form}

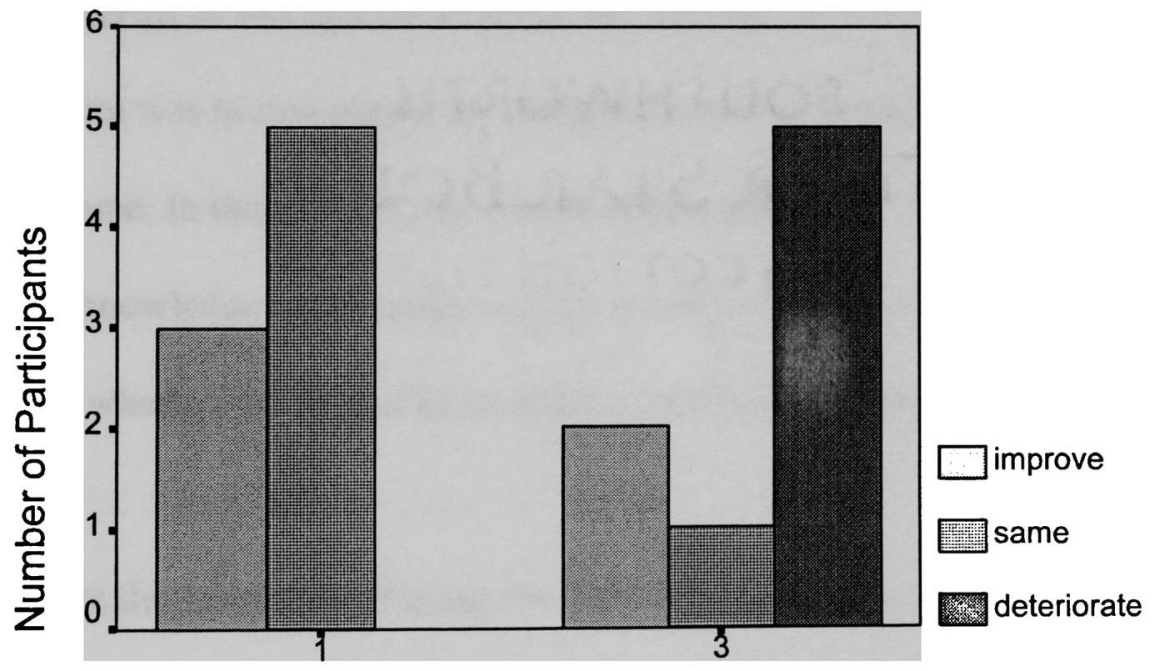

Group Number

Figure 3. Chi Square Results for the Youth Report Form 


\section{DISCUSSION}

This study sought to advance the development of efficacious interventions for use with the adolescent population by helping to close the knowledge gap with respect to assessing the impact of therapy process variables in group interventions with adolescent populations. The goal was to begin to evaluate the feasibility of assessing the impact of therapy process using a session-by-session process measure in a difficult to work with population of adolescents in a non-clinic setting. More specifically, one aim of this study was to investigate the feasibility of using the Session Evaluation Form (SEF), a session impact measure adapted for use with this population, in an intervention that targets at risk adolescents in a school-based setting. A second aim was to begin to investigate the utility of the measure in terms of its capacity to assess the differential session impact of therapy process. A third aim was to investigate the differential impact of session process on intervention outcome. In this context, the results of this study have the potential to contribute to our knowledge of the impact of some types of therapy processes at work in interventions and whether the impact of such processes has an influence on intervention outcome.

To evaluate the feasibility of using the SEF as a session impact measure with this population and the potential utility when used in this context, initial baseline data was collected on the SEF and outcome measures related to the intervention. Within the limitations of this sample, the findings from the study provide preliminary evidence for not only the feasible use of the measure with this population, but for the potential of the measure to differentially assess the impact of therapeutic process variables as perceived by the intervention participants. 
Feasibility of using the SEF with a difficult to work with population of adolescents in a school-based setting

The favorable response of these at risk adolescents to the final format of SEF provided qualitative evidence for the appropriateness of using the measure in the group interventions on a session-by-session basis. The study found that by changing the appearance and the administration of the SEF, the adolescent participants were able to stay task oriented and to maintain a positive and cooperative attitude toward filling out the form every week. More specifically, changing the wording and the layout helped to improve the presentation and changing the presence of the facilitator and adding more specific instructions helped to improve the administration.

Utility of the SEF as a measure of the impact of therapy process

A second research aim of the study focused on the utility of the SEF as a measure of session impact. More specifically, it focused on the capacity of the SEF to assess the differential impact of markers of process across intervention groups within the population. This question was thus concerned with the degree to which the measure was capable of assessing differences in impact of therapy processes such as relationship impacts (i.e., facilitator support, group support) and task impacts (i.e., skills acquisition, personal exploration) during group sessions. The results provided support for the ability of the SEF to measure differences in session impact.

In this study, support for the ability of the SEF to measure differences in session impact can be seen in the finding of a significant difference between Groups 1, 2, and 3 on the Facilitator Impact subscale. The Facilitator Impact subscale, it was noted, is one of the two relationship impact scales on the SEF. This subscale was designed to assess the 
impact of the therapeutic relationship between participant and the facilitator during the session. More specifically, the Facilitator Impact subscale assessed the group participants' perception of the degree of understanding and support provided by the group facilitator. The significant difference between Groups 1 and 3 on the Group Support, Skills Impact, and Exploration Impact subscales provide further support for the ability of the SEF to measure differences in session impact. That is, the SEF was able to assess the differences between a group with low session impact ratings (Group 3) and a group with high session impact ratings (Group 1) on several markers of therapy process.

These results also revealed three unexpected findings with a number of potentially significant implications. First, the pattern of the Facilitator Impact subscale results, indicating a significant difference between the groups, in conjunction with the different levels of experience between facilitators, suggests that therapist experience may be a significant contributor to perceived therapy impact. That is, one way to interpret these results is that the most experienced facilitator tended to be perceived by the members of the group as providing significantly greater understanding and support on a session by session basis than the least experienced facilitator. The facilitator in this group tended to be perceived as providing significantly less understanding and support.

This finding supports the co-constructivist view that the relationship of intervention participants to the facilitator is an important component of a successful intervention. Rogers (1959), it was noted, believed that if the therapeutic conditions such as unconditional positive regard, empathy, and genuineness were present, then the therapeutic process would take place on it's own. This finding is also in agreement with Maslow's view that through a warm relationship with the therapist the client would 
satisfy their needs for loving and belongingness and therefore be free to independently achieve ultimate psychological growth (Maslow, 1970).

A second implication from this line of evidence is that for the sample used in this study, Facilitator Impact was more significant to group participants, across the groups, than Group Impact. In contrast to the findings with the Facilitator Impact scale, the results obtained with the Group Impact scale did not yield a significant difference between the groups, although the results approached significance. More specifically, the ANOVAs indicated that the differences for the Group Impact score were not significant until it was further examined by dividing it into component parts (Group Cohesion and Group Support). Further examination indicated that the differences for Group Cohesion were not significant, but the differences for Group Support were significant.

Moreover, the results once again indicated that not only were there significant differences between the groups, but also that the pattern of results was consistent with the implication that the difference may be accounted for by differential therapist experience. That is, the group with the most experienced facilitator was perceived as providing significantly greater group support on a session by session basis than the group with the least experienced facilitator. This group was likely to be perceived as providing significantly less support.

In addition to its emphasis on the importance of the relationship of intervention participants to the facilitator, the co-constructivist approach also considers the context of a group intervention (interpersonal processes that occur between the individual and the group during the group sessions) to provide an important opportunity for the group, through the process of mutual disclosure, to facilitate exploration in participants in the 
group. That is, that the participants' affiliation with the intervention group (assuming that the group provides a cohesive, trusting, and caring context) provides an additional opportunity for the intervention participants to explore their own and the needs of others. The view that the content of a group intervention provides an important therapeutic context is consistent with findings by MacKenzie and Tschuschke (1993) that relatedness, defined as an individual's attachment to and comfort with the group, correlated positively with better therapy outcome.

In addition to its emphasis on the importance of the "therapeutic" relationship in the intervention, the Youth Development Program was developed to use a multifaceted format consisting of intervention strategies drawn from both the cognitive behavioral tradition and the interpersonal tradition that target increasing content knowledge about relationship issues and using relationship issues to foster exploration for awareness of identity and intimacy issues. With this in mind, the third implication from this line of evidence is that the group with the most experienced facilitator was perceived as producing significantly greater skills development and fostering significantly greater personal exploration than the group with the least experienced facilitator. As noted in the results section, the largest mean difference was between Group 1 and Group 3 on the Exploration Impact subscale. This subscale measured the degree to which the participants felt that they were able to participate and the degree to which they felt that they were helped by the discussion. The results suggest the possibility that the more experienced leader gave group participants more of an opportunity to participate equally in the discussions than the least experienced leader. This increased participation may also have contributed to the higher rate of improvement scores on the outcome measures for 


\section{Group 1.}

\section{Utility of the SEF as a predictor of intervention outcome}

The final goal of the study focused on the impact of therapy process across sessions and its relationship to intervention outcome. Previous research with the Promoting Youth Development (PYD) program has provided support for the impact of the developmental processes targeted by the intervention ( Ferrer-Wreder et al.; 2000/in press); Lorente, 1998; 1999). However, there has been no previous research on the impact of specific types of therapy processes that may contribute to intervention outcome for this program. Consequently, the final aim of this study was to begin to investigate possible links between differential session impact and the effects of the intervention (pre to post) on the developmental processes postulated to be related to promoting identity and intimacy development. The aim thus concerned the main effects of the intervention and their interaction with the impact of group process.

The results from the exploratory analysis provided preliminary and tentative support for the utility of the SEF as a predictor of intervention outcome. Trends in the outcome results tended to follow the same pattern observed with the impact of the process variables, with Group 1(the group with the highest ratings on the SEF) primarily changing in the improvement direction on the outcome measures and Group 3 (the group with the lowest ratings on the SEF ) mostly either not changing or in some cases deteriorating. Further, the pattern of change (Group 1 improving and Group 3 staying the same or deteriorating) was consistent across a number of variables. These trends in the data suggested the level of the significance of the pre to post test effects of the intervention may have been moderated by intervention group. 


\section{Limitations}

Although, these results provide some support for the hypotheses in this study, it should be noted that this was a preliminary feasibility study and the results are clearly viewed as tentative and exploratory. It is recommended that future studies should attempt to replicate these results and further delineate the makers of processes such as Group Impact, Facilitator Impact, Skills Impact and Exploration Impact. Future research should also be conducted using a larger sample size and more groups. Due to limited resources such as time, personnel and money, this study was hampered in terms of sample size and the number of groups.

Another limitation of these findings is that the data gathered from this study were based on participant reports alone. However, those researchers who follow the clientcentered perspective emphasize the need to assess therapeutic experiences from the client's perspective because only the client can tell you about their inner experiences (Barrett-Lennard, 1986; Orlinsky \& Howard, 1975). Horvath \& Symons (1991) also conducted a meta-analysis focusing on working alliance and therapeutic outcome and they found that working alliance was more positively correlated with client-rated outcome than outcome rated by an observer or the therapist. They also found that other outcomes are also more positively correlated with client ratings (Horvath \& Symons, 1991).

One of the more controversial implications of this study is that the differences in ratings between groups were due to differences in the therapists' experience level. In the literature there are conflicting findings on therapy outcomes and the relationship to therapist experience level with some studies (e.g., Burlingame et al., 1989; Church, 1993; Gold \& Dole, 1989) finding that experience does influence outcome and some studies 
(e.g., Clementel-Jones, Malan, \& Trauer, 1990; Dunkle, 1996; Propst, Paris, \&

Rosberger, 1994) concluding that it does not influence outcome. In addition to including more therapists, perhaps as suggested by Elliot \& Wexler (1994) future studies could be done that focus on therapists who regularly receive high ratings and their characteristics in order to shed more light on this debate.

$\underline{\text { Conclusion }}$

This study was conducted in response to various calls to contribute more information to the treatment-process literature about different interventions and different therapeutic circumstances with different types of clients, specifically adolescents (Hill \& Corbett, 1993; Kaminer, 1994; Kazdin, 1995). This study also began to fill a notable gap in the literature not only concerning adolescent interventions in general (Hoag \& Burlingame, 1997; Kaminer, 1994) but, as a review of the literature indicated, the availability of session impact measures that can be used with this population in particular. In this frame, this study drew upon an ongoing school-based intervention that targets promoting positive development in at-risk adolescents in an ethnically diverse context.

Due to an additional interest in developing methods for evaluating the impact of process variables on a session-by-session basis, this study was undertaken to pioneer research with at-risk adolescents in interventions using this method (Elliott \&Wexler, 1994; Hill, Helms, Spiegel, \& Tichenor, 1988; Orlinsky \& Howard, 1986; Stiles \& Snow, 1984; Stiles, 1980). This included an effort to extend and to refine a procedure for assessing the session-by-session impact of the role of therapist and therapeutic processes and their relationship to intervention outcome using the Session Evaluation Form (SEF). The results of this preliminary feasibility study provided tentative support for the ability of the 
SEF to assess differential impact of the markers of process across intervention groups within the population. The results of this study also contribute to our knowledge of methods for designing more effective interventions for this population. 


\section{REFERENCES}

Archer, S. L. (Ed.). (1994). Interventions for adolescent identity development. Thousand Oaks, CA: Sage.

Balistreri, E., Busch-Rossnagel, N. A., \& Geisinger, K. F. (1995). Development and preliminary validation of the Ego Identity Process Questionnaire. Journal of Adolescence, 18, 179-190.

Beck, A. P., \& Lewis, C.M. (Eds.) (2000) The process of groups psychotherapy:Systems for analyzing change. Washington D.C.: American Psychological Association.

Berman, A., Schwartz, S., Kurtines, W., \& Berman, S. (2000, in press). Style and competence in identity formation: An empirical comparison of two distinct approaches. Journal of Adolescence.

Berman, S. L. (1996) ). Making Life Choices: Facilitating identity formation in young adults. Unpublished dissertation. Florida International University, Miami.

Berman, S. L., Kurtines, W. M., Silverman, W. K., \& Serafini, L. (1996). The impact of exposure to crime and violence on urban youth. American Journal of Orthopsychiatry, 66(3), 329-336.

Botvin, G. J., \& Dusenbury, L. (1987). Life skills training: A psychoeducational approach to substance-abuse prevention. In C. Maher \& J. Zins (Eds.), Psychoeducational interventions in the schools (pp. 26-45). New York: Pergamon.

Burlingame, G. M., Fuhriman, A., Paul, S. \& Ogles, B.M., (1989). Implementing a time-limited therapy program: Differential effects of training and experience. Psychotherapy 26(3), 303-313

Bussell, J. R., \& Kurtines, W. M. (1999).The Session Evaluation Form (SEF). Unpublished measure, Florida International University, Miami.

Camp, B. W. \& Bash, M. S. (1985). Think aloud: Increasing social and cognitive skill - a problem-solving program for children. Champaign, IL: Research Press.

Church, E., (1993). Reading the transference in adolescent psychotherapy: A comparison of novice and experienced therapists. Psychoanalytic Psychology 10(2). $187-205$ 
Clementel-Jones, C., Malan, D., \& Trauer, T. (1990). A retrospective follow-up study of 84 patients treated with individual psychoanalytic psychotherapy: Outcome and predictive factors. British Journal of Psychotherapy 6(4), 363-374

Cole.

Corey, G. (1997). Theory and practice of group counseling. Pacific, CA: Brooks

Côté, J. E. (1994). Adolescent storm and stress. Hillsdale, NJ: Lawrence Erlbaum.

Côté, J. E., \& Allahar, A. L. (1996). Generation on hold: Coming of age in the late twentieth century. New York: New York University Press.

Cramer, D. (1987). Self-esteem, advice giving, and the facilitative nature of close personal relationships. Person-Centered Review, 2, 99-110.

Cramer, D. (1988). Self-esteem and facilitative close personal relationships: A cross-lagged panel correlation analysis. British Journal of Social Psychology, 27, 115126.

Cramer, D. (1989) Self-esteem and the facilitativeness of parents and close friends. Person-Centered Review, 4, 61-76.

Cramer, D. (1990). Toward assessing the therapeutic value of Rogers's core conditions. Counseling Psychology Quarterly, 3, 57-68.

Dahlberg, L. L. (1998). Youth violence in the United States: Major trends, risk factors, and prevention approaches. American Journal of Preventive Medicine, 14 (4), 259-272.

Denzin, N. K., \& Lincoln, Y. S. (Eds.). (1994). Handbook of qualitative research. Thousand Oaks, CA: Sage.

Dunne, A., Thompson, W., \& Leitch, R. (2000). Adolescent males' experience of the counseling process. Journal of Adolescence, 23(1), 79-93.

Dunkle, J. H., (1996) Contribution of therapist experience and personal characteristics to the working alliance. Journal of Counseling Psychology 43(4), 456-460

Durlak, J. A. (1998). Common risk and protective factors in successful prevention programs. American Journal of Orthopsychiatry, 68, 512-520.

Elliot, R. (1985). Helpful and nonhelpful events in brief counseling interviews: An empirical taxonomy. Journal of Counseling Psychology,32, 307-322 
Elliott, R. , James E., Reimschuessel, C., Cislo, D., \& Sack, N. (1985). Significant events in the analysis of immediate therapeutic impacts. Psychotherapy, 22, 620-630.

Elliot, R. \& Wexler, M. M. (1994). Measuring the impact of sessions in processexperiential therapy of depression: The session impacts scale. Journal of Counseling Psychology,41, 166-174.

Erikson, E. H. (1950). Childhood and society. New York: Norton.

Erikson, E. H. (1968). Identity: Youth and crisis. New York: Norton.

Erikson, E. H. (1980). Identity and the life cycle. New York: Norton.

Ferrer-Wreder, L., Cass Lorente, C., Kurtines, W., Briones, E., Bussell, J., Berman, S., \& Arrufat, O. (2000, in press). Promoting identity development in marginalized youth. Journal of Adolescent Research

Ferrer-Wreder, L. A. (1996). Making life choices workshop: A classroom-based workshop for promoting resilience in adolescents at risk for problem behaviors. Unpublished master's thesis, Florida International University, Miami.

Freire, P. (1970). Pedagogy of the oppressed. (Myra Bergman Ramos, Trans.). New York: Herder and Herder.

Freire, P. (1983). The importance of the act of reading. Journal of Education, 165(1), 5-11.

Gardner, S. E., Green, P. F., \& Marcus, C. (1994). Signs of effectiveness II: Preventing alcohol, tobacco, and other drug use. (DHHS Publication No. ADM 301049/13664). Washington, DC: U.S. Government Printing Office.

Gesten, E., Weissberg, R., Amish, P., \& Smith, J. (1987). Social problem-solving training: A skills-based approach to prevention and treatment. In C. Maher \& J. Zins (Eds.), Psychoeducational interventions in the schools (pp. 26-45). New York: Pergamon.

Gold, J. \& Dole, A. A., (1989). Professional psychotherapists vs. nonpsychotherapists: Thought processes, verbal behavior, and clients' satisfaction. Psychological Reports 65(2), 611-620

Greenberger, E. \& Sorensen, A. B. (1973). Educating children for adulthood: A concept of psychosocial maturity. Found in: Center for Social Organization of Schools Report, Johns Hopkins U.,159, 53.

Grotevant, H. D. (1987). Toward a process model of identity formation. Journal of Adolescent Research, 2, 203-222. 
Grotevant, H. D., \& Cooper, C. R. (1981). Assessing adolescent identity in the areas of occupation, religion, politics, friendships, dating, and sex roles: Manual for the administration and coding of the interview. Journal Supplement Abstract Service Catalog of Selected Documents in Psychology, 11, 52-53 (Ms. No. 2295).

Habermas, J. (1979). Communication and the evolution of society. Boston: Beacon Press.

Harrist, R. S., Quintana, S. M., Strupp, H. H., \& Henry, W. P. (1994) Internalization of interpersonal process in time-limited dynamic psychotherapy. Psychotherapy 31(1), 49-57.

Henry, W. P., Schacht, T. E., \& Strupp, H. H., (1990) Patient and therapist introject, interpersonal process, and differential psychotherapy outcome. Journal of Consulting \& Clinical Psychology 58(6), 768-774.

Hill, C.E., \& Corbett, M. M. (1993) A perspective on the history of process and outcome research in counseling psychology. Journal of Counseling Psychology 40(1). 3-24.

Hill, C.E., Helms, J. E., Spiegel, S.B., \& Tichenor, V. (1988). Development of a system for categorizing client reactions to therapist interventions. Journal of Counseling Psychology, 35, 27-36.

Hill, C.E., Nutt, E. A., \& Jackson, S. (1994). Trends in psychotherapy process research: Samples, measures, researchers, and classic publications. Journal of Counseling Psychology 41(3), 364-377.

Hoag, M. J. \& Burlingame, G. M. (1997). Evaluating the effectiveness of child and adolescent group treatment: A meta-analytic review. Journal of Clinical Child Psychology 26(3), 234-246.

Kaminer, Y., Blitz, C., Burleson, J. A., Kadden, R. M., \& Rounsaville, B.J. (1998). Measuring treatment process in cognitive-behavioral and interactional group therapies for adolescent substance abusers. Journal of Nervous \& Mental Disease 186(7). 407-413.

Kaminer, Y. (1994). Adolescent substance abuse: A comprehensive guide to theory and practice. New York: Plenum Medical.

Kazdin, A. E. (1995). Scope of child and adolescent psychotherapy research: limited sampling of dysfunctions, treatments and client characteristics. Journal of Clinical Child Psychology ,24, 125-140. 
Kiesler, D.J. (1986). Foreword in L.S. Greenberg \& W.M. Pinsof (Eds.), The psychotherapeutic process :A research handbook (vii-xi). New York: Guilford Press.

Kirby, D. (1997). An impact evaluation of project SNAPP: An AIDS and pregnancy prevention middle school program. AIDS Education \& Prevention, 9(1), 14-30.

Kurtines, W. M. (1999). Human behavior and development: A co-constructivist perspective. Unpublished manuscript, Florida International University, Miami.

Lorente, C.C., (1999) Building better relationships program: Fostering interpersonal development in American high school adolescents. Unpublished Dissertation, Florida International University, Miami, Florida.

Lorente, C. C. (1998) Building better relationships workshop: An intervention fostering identity formation and interpersonal development in middle adolescents. Unpublished Master's Thesis, Florida International University, Miami, Florida.

Lorente, C. C. \& Adams, M. (1998). Development and validation of the relationship attitudes and values scale (RAVS). Unpublished measure, Florida International University, Miami.

MacKenzie, K. R. \& Tschuschke, V. (1993). Relatedness, group work, and outcome in long-term inpatient psychotherapy groups. Journal of Psychotherapy Practice and Research, 2 (2), 147-156.

Mallinckrodt, B. (1994). Session impact in counseling process research: Comment on Elliott and Wexler (1994) and Stiles et al. Journal of Counseling Psychology, 41(2), 186-190.

Marcia, J. E. (1966). Development and validation of ego identity status. Journal of Personality and Social Psychology, 5, 551-558.

Marcia, J. E. (1980). Identity in adolescence. In J. Adelson (Ed.), Adolescent Psychology (pp. 159-187). New York: Wiley.

Marcia, J. E., \& Archer, S. L. (1993). Identity status in late adolescents: Scoring criteria. In J. E. Marcia, A. S. Waterman, D. R. Matteson, S. L. Archer, \& J. L. Orlofsky (Eds.), Ego Identity: A Handbook for Psychosocial Research (pp. 205-240). New York: Springer-Verlag.

Maslow, A. H. (1970). Motivation and Personality (2nd ed). New York: Harper \& Row. 
Mellor, S. (1989). Gender differences in identity formation as a function of self-other relationships. Journal of Youth \& Adolescence, 18(4), 361-375.

Montgomery, M. J. \& Sorrel, G. T. (in press). Love attitudes among early adolescents. Journal of Adolescence.

Montemayor, R., Adams G. R. \& Gullota, T. P. (eds.) (1994). Personal relationships during adolescence. Thousand Oaks, CA: Sage.

Moore, S. \& Boldero, J. (1991). Psychosocial development and friendship functions in adolescence. Sex Roles, 25(9-10), 521-536.

Orlinsky, D. E., \& Howard, K. I. (1975). Varieties of psychotherapeutic experience. New York: Teachers College Press.

Orlinsky, D. E., \& Howard, K. I. (1977). The therapist's experience of psychotherapy. In A.S. Gurman \& A.M. Razin (Eds.), Effective psychotherapy: A handbook of research (pp. 566-589). New York: Pergamon Press.

Orlinsky, D. E., \& Howard, K. I. (1986). The psychological interior of psychotherapy: Explorations with the Therapy Sessions Reports. In L.S. Greenberg \& W.M. Pinsof (Eds.), The psychotherapeutic process: A research handbook (pp. 477-501). New York: Guilford Press.

Peplau, L. A., \& Campbell, S. M. (1989). The balance of power in dating and marriage. In J. Freeman (Ed.), Women: A feminist perspective (4th ed., pp. 121-137). Mountain View, CA: Mayfield.

Phillips, J. P. N. (1986). Shapiro personal questionnaire and generalized questionnaire techniques: a repeated measures individualized outcome measurement. In L.S. Greenberg \& W.M. Pinsof (Eds.), The psychotherapeutic process: A research handbook (pp. 557-590). New York: Guilford Press.

Propst, A., Paris, J.\& Rosberger, Z. (1994) Do therapist experience, diagnosis and functional level predict outcome in short term psychotherapy? Canadian Journal of Psychiatry 39(3), 168-176.

Raskin, P. M., \& Waterman, A. S. (1994). On the bidirectional impact of counseling on identity and intimacy development. In S. L. Archer (ed.), Intervention for Adolescent Development (pp. 214-220). Thousand Oaks, CA: Sage.

Rogers, C. R. (1959). A theory of therapy, personality, and interpersonal relationships, as developed in the client-centered framework. In S. Koch (Ed.), Psychology: A study of science. (Vol. 3) New York: McGraw-Hill. 
Rosenthal, D. A, Gurney R. M., \& Moore, S. M. (1981). From trust to intimacy: A new inventory for examining Erikson's stages of psychosocial development. Journal of Youth and Adolescence, 10, 117-135.

Rutter, M. (1990). Psychosocial resilience and protective mechanisms. In J. Rolf, A. S. Masten, D. Cicchetti, K. H. Neuchterlein, \& E. Weintraub (Eds.). Risk and protective factors in the development of psychopathology (pp. 181-214). New York: Cambridge University Press.

Rutter, M., Giller, H., \& Hagell, A. (1998). Antisocial behavior by young people. New York: Cambridge University Press.

Samuels, D. \& Samuels, M. (1975). The complete handbook of peer counseling: An authoritative guide for the organization, training, implementation and evaluation of a peer counseling program. Miami, FL: Fiesta Publishing.

Sosa-Biziack, L., Ferrer-Wreder, L. A., Schwartz, S. J., Kurtines, W. M. (1999 May). The critical problem solving scale (CPSS): Making life choices. Paper presented at the sixth annual meeting of the Society for Research on Identity Formation, London, Ontario, Canada.

Spivack, G., Platt, J. J., \& Shure, M. B. (1976). The problem-solving approach to adjustment. San Francisco: Jossey-Bass.

Spivack, G., \& Shure, M. B. (1982). The cognition of social adjustment: Interpersonal cognitive problem-solving and thinking. In B. B. Lahey, \& A. E. Kazdin (Eds.), Advances in clinical psychology (vol. 5). (pp. 323-372). New York: Plenum.

Stiles, W. B. (1980). Measurement of the impact of psychotherapy sessions. Journal of Consulting and Clinical Psychology, 48, 176-185.

Stiles, W. B. \& Snow, J. S. (1984). Counseling session impact as viewed by novice counselors and their clients. Journal of Consulting and Clinical Psychology, 31 , 3-12.

Stiles, W. B., Tupler, L. A., \& Carpenter, J. C. (1982). Participants' perceptions of self-analytic group sessions. Small Group Behavior 13(2), 237-254.

Stiles, W.B., Reynolds, S., Hardy, G. E., Rees, A., Barkham, M., \& Shapiro, D. A. (1994). Evaluation and description of psychotherapy sessions by clients using the Session Evaluation Questionnaire and the Session Impacts Scale.Journal of Counseling Psychology 41(2), 175-185.

Sullivan, H.S.(1954). The psychiatric interview. New York: Norton. 
Tait, G. (1993). Youth, personhood and practices of the self: Some new directions for youth research. Australia and New Zealand Journal of Sociology, 29, 40-54.

Waterman, A. S. (1994). Ethical considerations in interventions for promoting identity development. In S. L. Archer, (Ed.), Interventions for adolescent identity development. (pp. 231-244). Thousand Oaks, CA: Sage. Waterman, 1994

Webster-Stratton, C., \& Taylor, T. K. (1998). Adopting and implementing empirically supported interventions: A recipe for success. In A. Buchanan \& B. L. Hudson (Eds.), Parenting, schooling, and children's behavior (pp. 127-160). Ashgate Publishing Company.

West, L. L. (1991). Effective strategies for dropout prevention of at-risk youth. Gaithersburg, MA: Aspen.

Wilson, D. K., Rodriguez, J. R., \& Taylor, W. C. (1997). Health-promoting and health-compromising behaviors among minority adolescents. Washington, DC: American Psychological Association. 


\section{APPENDIX}

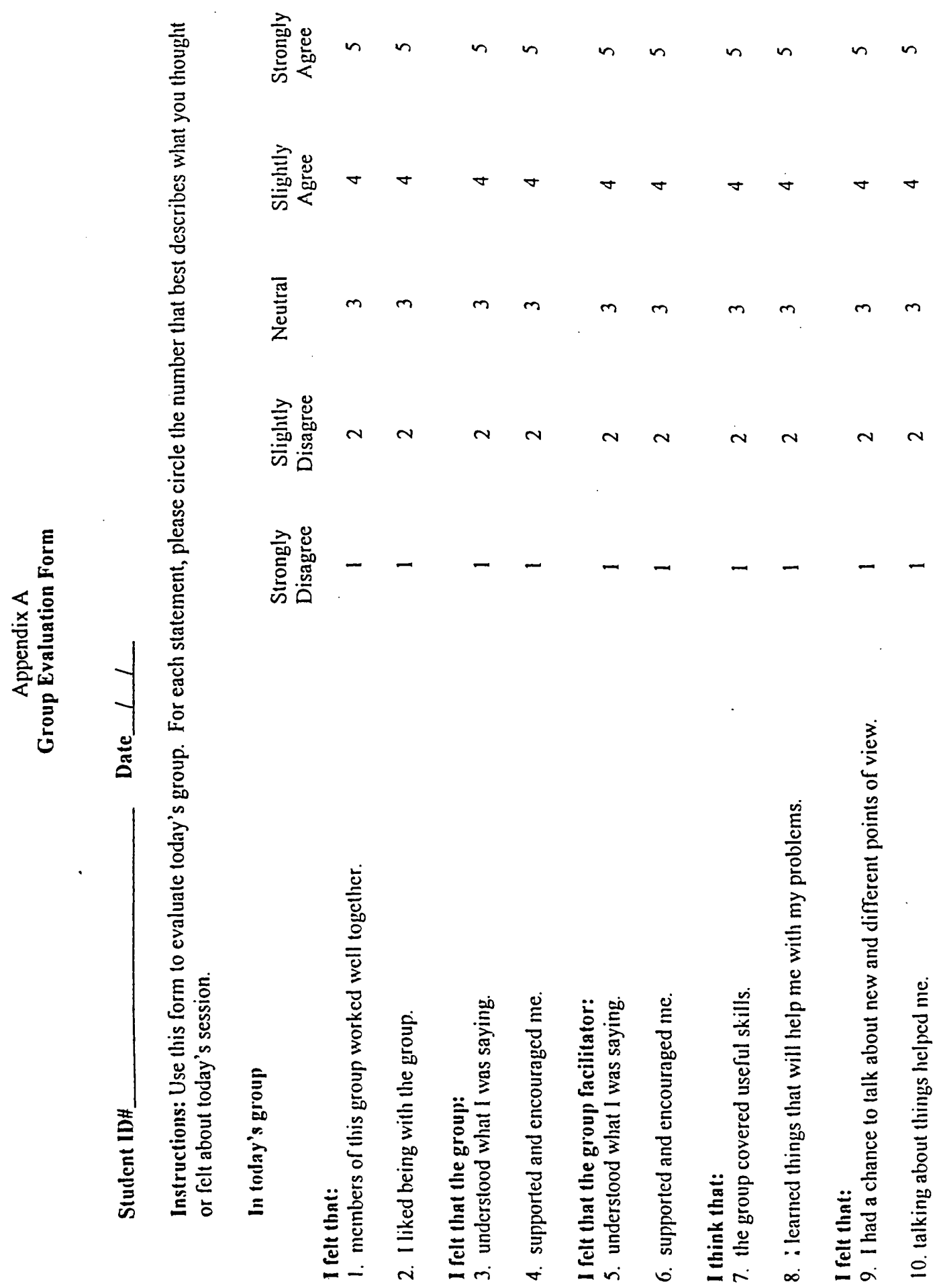




\section{VITA}

\section{JANENE R. BUSSELL}

1993

1996-2000

$1997-2000$

1998

\author{
B.A., Psychology \\ Florida Atlantic University \\ Boca Raton, Florida
}

Graduate Assistant

Florida International University

Miami, Florida

Therapist Intern

Florida International University

Miami, Florida

M.S., Psychology

Florida International University

Miami, Florida

\section{PUBLICATIONS AND PRESENTATIONS}

Bussell, J.R., Kurtines, W., Larios, V., Romageura, D. \& Timms, D. (April, 2000) Exploring the Effects of Therapeutic Process on Interventions Targeting Adolescent Identity and Intimacy. Poster presentation at the Society for Research on Identity Formation, Chicago, Illinois.

Cass Lorente, C., Ferrer-Wreder, L., Bussell, J., Adams, M., Kurtines, W. \& Berman A. (May, 1999). Building better relationships: Fostering identity and intimacy development in middle adolescents at-risk for problem behaviors. Symposium presentation at the Society for Research on Identity Formation, London, Ontario.

Ferrer Wreder, L., Lorente, C. C., Briones, E., Bussell, J. R., Kurtines, W. K., \& Berman, S.. (1997, March). Making Life Choices Intervention: Refinement and Recent Work. Presentation at Florida Society for Research on Identity Development, Miami, FL.

Ferrer Wreder, L., Lorente, C. C., Kurtines, W. K., Briones, E., Bussell, J. R., \& Schwinghammer, A. (1997, April) Making Life Choices Workshop: A Classroom-Based Workshop for Promoting Resilience in Adolescents at Risk for Problem Behaviors. Presentation at Society for Research in Child Development, Washington, D.C. 
Ferrer Wreder, L., Lorente, C. C., Briones, E., Bussell, J. R., Kurtines, W. K., \& Berman, S. (1998, February) The Making Life Choices Youth Intervention. Presentation at Society for Research on Adolescence, San Diego, CA.

Ferrer-Wreder, L., Cass Lorente, C., Bussell, J., Adams, M., Briones, E., Berman, S., Arrufat, O. \& Kurtines, W. (April, 1999). Making life choices: Encouraging identity development in American adolescents atrisk for problem behaviors. Poster presentation for the Society for Research on Child Development, Albuquerque, New Mexico.

Ferrer-Wreder, L., Cass Lorente, C., Bussell, J., Adams, M., Briones, E., Berman, S., Arrufat, O. \& Kurtines, W. (May, 1999). Making life choices: Encouraging identity development in middle adolescents at-risk for problem behaviors. Symposium presentation at the Society for Research on Identity Formation, London, Ontario.

Ferrer-Wreder, L., Cass Lorente, C., Kurtines, W., Briones, E., Bussell, J., Berman, S., \& Arrufat, O. (2000, in press). Promoting identity development in marginalized youth. Journal of Adolescent Research.

Lorente, C.C., Ferrer Wreder, L., Kurtines, W. K., Bussell, J. R., \& Berman, A. (1997, March). Building Better Relationships Workshop: A Psychosocial Intervention for Middle Adolescents. Presentation at Florida Society for Research on Identity Development, Miami, FL.

Lorente, C.C., Ferrer-Wreder, L., Adams, M., Bussell, J. (2000, March). Building Better Relationships Workshop: An intervention fostering identity and intimacy development in middle adolescents. Poster presentation at the biennial meeting of the Society for Research on Adolescence, Chicago, $\mathbb{I}$. 